\title{
AGEING AND RETAIL DISPLAY TIME IN RAW BEEF ODOUR ACCORDING TO THE DEGREE OF LIPID OXIDATION
}

Virginia C. Resconi ${ }^{1, *}$, Mónica Bueno ${ }^{2}$, Ana Escudero², Danielle Magalhaes ${ }^{1}$, Vicente Ferreira $^{2}$ and M. Mar Campo ${ }^{1}$

${ }^{1}$ Department of Animal Production and Food Science, Faculty of Veterinary, Instituto Agroalimentario de Aragón IA2, Universidad de Zaragoza - CITA, 50013 Zaragoza, Spain.

${ }^{2}$ Laboratory for Flavor Analysis and Enology (LAAE), Department of Analytical Chemistry, Faculty of Sciences, Instituto Agroalimentario de Aragón IA2, Universidad de Zaragoza - CITA, Associate unit to Instituto de las Ciencias de la Vid y del Vino ICVV- (UR-CSIC-GR), 50009 Zaragoza, Spain.

* Corresponding author: Tel: + 34976 761000; Fax: +34 976 761590;

E-mail address: resconi@unizar.es

\begin{abstract}
This study aims to assess the changes in beef aroma over time when steaks are stored in retail display under high oxygen conditions from pre-aged knuckles for 15 or 22 days in vacuum conditions. Odorous volatile compounds were analysed by solid phase microextraction (SPME) / gas chromatography mass spectrometry (GC-MS). Results were grouped as low, medium and high oxidative groups according to thiobarbituric acid reacting substances values after 9 days of display. The intensity of off-odours in the raw meat increased with ageing and display time and oxidative groups. Based in correlations between the variables and regressions of the compounds through display, eight compounds were proposed as odour shelf-life markers. Among them, five were
\end{abstract}


most sensitive and precise in all oxidative groups: 1-hexanol in meat aged for 15 days, ethyl- octanoate and 2-pentylfuran in meat aged for 22 days, and penta and hexanoic acids in the two studied ageing times.

\section{KEYWORDS}

SPME-GCMS, volatile compounds, meat aroma, modified atmosphere packaging, meat quality 


\section{INTRODUCTION}

Beef is usually aged for 7 to 21 days in order to improve tenderness and homogeneity, being the optimum period dependent on several factors, including the muscle type and the breed under consideration (Monsón, Sañudo \& Sierra, 2005; Thompson, 2002). In addition, ageing could affect other quality parameters, such as odour, taste and flavour in the cooked meat due to the change in the concentration of precursors (Koutsidis, Elmore, Oruna-Concha, Campo, Wood \& Mottram, 2008; Meinert et al., 2009), but also to the development of odorous compounds in the raw product coming from chemical and enzymatic reactions and bacterial action (Casaburi, Piombino, Nychas, Villani \& Ercolini, 2015; Estévez, Morcuende, Ventanas \& Cava, 2003; Insausti, Beriain, Gorraiz $\&$ Purroy, 2002). The mentioned processes occur even when ageing is conducted at refrigeration, vacuum and dark conditions. Nevertheless, after cooking the meat could reach high flavour acceptability scores (Colle et al., 2015; Pérez-Juan et al., 2014; Smith et al., 2008). In fact, ageing up to 21 days improves the flavour in some beef breeds (Monsón et al., 2005).

Commonly, after ageing the meat is packed and preserved in retail display during some days until purchasing. It has been shown that steaks displayed without oxygen improve the eating quality (Aaslyng, Tørngren \& Madsen, 2010), but at commercial level steaks are still mostly sold in oxygen-permeable overwrap or in packs with high oxygen levels due to colour issues. Previous studies found unacceptable rancid flavour developed in beef Longissimus dorsi displayed for around nine days in high oxygen packs (Campo, Nute, Hughes, Enser, Wood \& Richardson, 2006; Resconi, Escudero, Beltrán, Olleta, Sañudo \& Campo, 2012), but shorter or extended periods of odour shelf-life would occur depending on numerous factors such as the antioxidant status of the meat. In a study with lambs, for example, dietary supplementation of vitamin E led to lower levels 
of lipid oxidation derived compounds, such as 2-heptanone and 1-penten-3-ol in the cooked meat (Rivas-Cañedo et al., 2013), which may affect the odour perception of the meat.

The effect of time when ageing the meat or when stored in retail display under high oxygen conditions in the beef aroma development has been previously studied using cooked samples (Campo et al., 2006; Gorraiz, Beriain, Chasco \& Insausti, 2002; Ma, Hamid, Bekhit, Robertson \& Law, 2012; O'Quinn et al., 2016; Resconi et al., 2012; Stetzer, Cadwallader, Singh, McKeith \& Brewer, 2008; Watanabe, Kamada, Imanari, Shiba, Yonai \& Muramoto, 2015), but less has been published regarding the raw meat (Insausti et al., 2002; La Storia et al., 2012; Saraiva, Oliveira, Silva, Martins, Ventanas \& García, 2015). Most studies have used cooked meat matching the frequent way of consumption, but also because a richer variety and intensity of aromas is developed (Resconi, Escudero \& Campo, 2013). The odour of the raw meat in the store while buying is becoming less important since the meat is usually sold packaged. However, when opening the package at home, the odour should be agreeable for the consumer (Schindler, Krings, Berger \& Orlien, 2010). Furthermore, some compounds already present or developed in the raw meat, remain after cooking and could affect the flavour perception (Insausti et al., 2002; Rota \& Schieberle, 2005; Schindler et al., 2010).

The aim of this study was to evaluate the effect of display time on the odour characteristics and the volatile compounds involved in raw knuckle beef steaks preaged under vacuum conditions during 15 or 22 days, according to the extent of lipid oxidation. Furthermore, it also aims to identify shelf-life markers between the volatile compounds analysed. It is already known that lipid oxidation affects odour development; therefore samples will be grouped by their oxidative potential, since 
different key compounds may affect the change in the aroma characteristics through display.

\section{MATERIAL AND METHODS}

\subsection{Samples, ageing and display conditions}

This study used 48 crossbred entire young bulls 12.8-13.9 mo with a cold carcass weight of 231-340 kg and an intramuscular fat content in longissimus thoracis muscle of 1.5-2.5\%. The animals were raised on the same farm and fed concentrates (based on maize, barley and soya) and cereal straw ad libitum. After slaughtering in a commercial abattoir following standard procedures meeting welfare regulations, both knuckles from each animal were obtained, vacuum packaged and aged for either 15 days (left side) or 22 days (right side), in the dark at $3 \pm 1{ }^{\circ} \mathrm{C}$. Then, 0.6 - $\mathrm{cm}$ thick steaks were obtained and randomly allocated for each display time. Samples from each animal were distributed in all ageing and display times. The samples from day 0 of display were analysed within the day of sampling, whereas the rest of the steaks were placed individually in polyethylene commercial trays, flushed with a food-grade gas mixture: $80 \%$ of oxygen and $20 \%$ of carbon dioxide, as commonly used at commercial level, and sealed with a polyethylene and polyamide laminate film $(50 \mu \mathrm{m}$, water vapour transmission rate of $\mathrm{b} 5$ $\mathrm{g} / \mathrm{m}^{2}$.day at $23{ }^{\circ} \mathrm{C}$ and $85 \% \mathrm{RH}$, an $\mathrm{O}_{2}$ transmission rate of $\mathrm{b} 5 \mathrm{~cm}^{3} / \mathrm{m}^{2}$. day at $23{ }^{\circ} \mathrm{C}$ and $0 \% \mathrm{RH}$ and a $\mathrm{CO}_{2}$ transmission rate of $\mathrm{b} 25 \mathrm{~cm}^{3} / \mathrm{m}^{2}$. day at $23{ }^{\circ} \mathrm{C}$ and $0 \% \mathrm{RH}$; Linpac Packaging S.L., Spain). Then, trays were placed in simulated retail display (Koxka, V1VI1-5; Pamplona, Spain), under light (cool white fluorescent illumination, 1200 lux, 16 h on, 8 off, Mazdafluor Aviva TF/36w; Philips, Eindhoven, Holland), at $4{ }^{\circ} \mathrm{C} \pm 1{ }^{\circ} \mathrm{C}$ for 5, 7 or 9 days. Lipid oxidation, odour and volatile compounds analyses were 
conducted in the rectus femoris muscle from the same steak. Such muscle was minced and aliquots for each analysis were immediately taken.

\subsection{Lipid oxidation and oxidative groups}

Lipid oxidation was measured with the thiobarbituric acid reactive substances (TBARS) method of Pfalzgraf, Frigg and Steinhart (1995). Meat samples of $10 \mathrm{~g}$ were homogenized with $20 \mathrm{~mL}$ of trichloroacetic acid (10\%, VWR) using an Ultra-Turrax T25 (Janke \& Kunkel, Staufen, Germany). Samples were centrifuged (Gyrozen 1248R, Daejeon, Korea) at $4000 \mathrm{rpm}$ for $30 \mathrm{~min}$ at $4{ }^{\circ} \mathrm{C}$ and the supernatants filtered through qualitative paper (F1093 grade, Chmlab, Barcelona, Spain). Two millilitres of the filtrates were taken in duplicates and mixed with $2 \mathrm{~mL}$ of thiobarbituric acid $(20 \mathrm{mM}$, Sigma, Aldrich), homogenized and incubated for 20 min in a water bath (Grant W14, Cambridge, UK) at $97{ }^{\circ} \mathrm{C}$. Absorbance was measured at $532 \mathrm{~nm}$ (spectrophotometer Unicam 5625 UVNIS, Cambridge, UK). TBARS values were calculated from a daily standard curve of 1,1,3,3-tetramethoxypropane (TMP, Sigma Aldrich), and expressed as mg malondialdehyde (MDA)/kg sample. Based on the results obtained at day 9 of display in pre-aged knuckles for 15 days, samples were grouped according to the extent of lipid oxidation in low oxidative ( $n=16$ animals/ageing), when less than $1 \mathrm{mg}$ MDA/kg was obtained, medium ( $n=15$ animals/ageing), when TBARS values between 1-2 mg MDA/kg were found and high oxidative ( $n=17$ animals/ageing), when TBARS value exceeded 2 (Campo et al., 2006). Thus, each animal was allocated in a single level of oxidation.

\subsection{Volatile compounds analysis}




\subsubsection{Chemicals}

Dipropylene glycol 99\% was supplied by Alfa Aesar (Karlsruhe, Germany); (E,E)-2,4decadienal $\geq 89 \%$ by Lancaster Synthesis (Eastgate, UK); butanoic acid $99.5 \%$, pentanoic acid 98\%, octanoic acid 98\%, ethyl hexanoate $99 \%$ and 1-octen-3-one $>99 \%$ by Fluka (Madrid Spain); hexanoic acid 99.5\%, heptanoic acid 99\%, nonanoic acid $\geq 96 \%$, decanoic acid $\geq 98 \%$, hexanal $98 \%$, nonanal 95\%, (E)-2-heptenal $\geq 95 \%$, (E)-2octenal 94\%, (E)-2-nonenal 97\%, (E,E)-2,4-nonadienal $\geq 85 \%$, (E)-2-undecenal $\geq 95 \%$, phenylacetaldehyde $>95 \%$, 2-butanone $>99 \%$, 2-heptanone $\geq 98 \%$, 3-octanone $\geq 98 \%$, 2octanone $\geq 98 \%, \quad 2$-nonanone $\geq 99 \%, 3$-octen-2-one $\geq 98 \%$, 3-nonen-2-one 95\%, 1 hexanol 98\%, 1-octen-3-ol 98\%, ethyl octanoate $\geq 98 \%$, methyl 2-methylbutanoate $\geq 98 \%$ and 2-pentylfuran $\geq 98$ by Aldrich (Madrid, Spain). The compounds (Z)-2-octenal and (E,Z)-2,4-decadienal were found in commercial (E)-2-octenal and (E,E)-2,4decadienal, respectively.

\subsubsection{Sample preparation and extraction by HS-SPME}

For each steak, $4 \mathrm{~g}( \pm 0.001)$ of minced meat was collected in the bottom of $20 \mathrm{~mL}$ SPME vial. The vial was purged for 20 seconds with nitrogen and immediately crimp capped to avoid the presence of oxygen in the headspace. Samples were kept at $4{ }^{\circ} \mathrm{C}$ until analysis.

The vial was then equilibrated at $37^{\circ} \mathrm{C}$ for $10 \mathrm{~min}$ in the automated sample preparation unit. After that, a polydimethylsiloxane/divinilbenzene (PDMS/DVB) $65 \mu \mathrm{m}$ film thickness fibre (Supelco-Spain, Madrid, Spain) was exposed to the headspace of the unstirred sample for $40 \mathrm{~min}$ at $37^{\circ} \mathrm{C}$ and then desorbed directly in the injection port of the chromatographic system in the conditions detailed below. After desorption, the fibre 
was cleaned for $10 \mathrm{~min}$ at $250{ }^{\circ} \mathrm{C}$ in the back out unit. Total automation of the extraction procedure was achieved using a CTC CombiPAL autosampler (Zwingen, Switzerland), which was programmed using the CycleComposer with macroeditor software and equipped with sample trays and temperature controlled incubator tray.

\subsubsection{Gas chromatography-mass spectrometry conditions}

The instrument was a CP-3800 chromatograph coupled to a Saturn 2200 ion trap mass spectrometric detection system supplied by Varian (Sunnyvale, CA, USA). The fibre was desorbed directly in the injection port of the GC-MS in splitless mode for $5 \mathrm{~min}$ at $250{ }^{\circ} \mathrm{C}$ and a pressure pulse of 30 psi during this period of time (the column flow during this period of time was $2 \mathrm{~mL} / \mathrm{min}$ ). Helium was the carrier gas at a flow rate of 1 $\mathrm{mL} / \mathrm{min}$.

A DB-WAXETR capillary column (J\&W Scientific, Folsom, CA, USA) of $60 \mathrm{~m} \times 0.25$ mm I.D., a film thickness of $0.25 \mu \mathrm{m}$, and preceded by a $3 \mathrm{~m} \times 0.25 \mathrm{~mm}$ uncoated (deactivate, intermediate polarity) precolumn from Supelco-Spain was used. The oven temperature was initially $40{ }^{\circ} \mathrm{C}$ during $10 \mathrm{~min}$, then raised by $4{ }^{\circ} \mathrm{C} / \mathrm{min}$ to $140{ }^{\circ} \mathrm{C}$, followed by a rate of $10{ }^{\circ} \mathrm{C} / \mathrm{min}$ to $220^{\circ} \mathrm{C}$ and finally held at this temperature for $5 \mathrm{~min}$. The MS parameters were a transfer line temperature of $230^{\circ} \mathrm{C}$ and a trap temperature of $170{ }^{\circ} \mathrm{C}$ with emission current of $80 \mu \mathrm{A}$. The global run time was recorded in full scan mode (33-300 m/z mass range). The chromatographic data were analysed by Varian Saturn GC-MS Workstation Version 5.52 software. The identity of 32 odorants was determined through the mass spectra and the linear retention indices and confirmed by the injection of the pure reference standards when available. 
Given that some of the selected analytes did not give a signal in TIC or else appeared together with peaks of interference that make it difficult to integrate, it was decided to consider selective mass.

The quantitation of the compounds using selective mass was carried out applying a response factor obtained calculated with a dipropylene glycol control solution analysed by GC-MS every 16 meat samples. This control solution contained a compound of each family to which its response factor was calculated. This response factor was subsequently applied to all compounds of the same family: butanoic acid (acids), 1hexanol (alcohols), nonanal (saturated aldehydes), (E)-2-nonenal (alkenals), methyl 2methylbutanoate (esters), 3-octanone (saturated ketones), 1-octen-3-one (unsaturated ketones) and 2-pentylfuran.

\subsection{Odour characterisation}

The sensory analysis was conducted by six panellists, one male and five females, from 30 to 58 years old, experienced in the sensory analysis of meat and meat products. Descriptors were developed by consulting bibliography (Schevey, Toshkov \& Brewer, 2013) and by agreement of the members in a session where two samples of raw beef (a vacuum packed sample and a sample stored seven days in high oxygen pack) were presented for training. Panellists rated the intensity of the odour, using a lineal scale from 0 (no detected) to 10 (very intense odour). The seven descriptors were: raw meat odour (odour associate with raw minced beef), rancid odour (odour associated with oxidized fat), metallic odour (odour associated with a ferrous sulphate solution), sweet odour (odour associated with sugar), musty odour (odour associated with a wet 
cardboard/highly humid room), cooked meat odour (odour associated with a stewed beef) and sulphur odour (odour associated with a cooked yolk of an egg).

Similarly and simultaneously than for the volatile analysis, after opening the package at each day of display, steaks were minced and $4 \mathrm{~g}$ were transferred to a snap clap glass vials $(20 \mathrm{~mL})$ and kept at $4 \pm 2{ }^{\circ} \mathrm{C}$ until the evaluation within three hours of preparation. The evaluation was performed in a room with controlled temperature $\left(20^{\circ} \mathrm{C}\right)$. The samples were tempered at room temperature for $30 \mathrm{~min}$ before analysed. Panellists sniffed the same vial on intervals of at least $15 \mathrm{~min}$ to allow the aroma compounds to reach the balance in the headspace.

\subsection{Data analysis}

A General Linear Model (GLM) was applied with oxidative group (<1 (low), 1-2 (medium), >2 mg (high) MDA/kg) ageing (15 and 22 days) and display time (0, 5, 7, 9 days) as fixed effects. Since interactions were significant $(P \leq 0.05)$, data were analysed within ageing and oxidative group with display time as fixed effect and within ageing and display time with oxidative group as fixed effect. A Tukey test was performed to show differences between display days and oxidative groups. Linear and exponential regressions for the volatile compounds through display were conducted. Finally, Pearson correlations between the variables studied were performed. All the statistical analyses were carried out with SPSS (v22.0).

\section{RESULTS AND DISCUSSION}


The experiment was performed to evaluate the behaviour of odorous volatile compounds and odour characteristics from raw knuckle beef steaks during display in high oxygen modified atmosphere packing (MAP) and pre-aged during 15 or 22 days, according to their lipid oxidation potential. The large number of samples used (at least 15 samples per oxidative group) makes the data reliable. The target aroma compounds were selected having regard to the scientific literature of raw beef (Casaburi et al., 2015; Insausti et al., 2002; Panseri et al., 2015; Pérez, Rojo, González \& Lorenzo, 2008; Saraiva et al., 2015; Schindler et al., 2010). In Table 1 the list of variables, the main effects studied and their interactions are presented. Since many interactions were found, Table 2 shows the mean concentration of the volatile compounds within lipid oxidation group (low, medium and high) and display time for the meat pre-aged for 15 days, whereas for 22 days they are presented in Table 3. Similarly, the results of the sensory analysis and TBARS values are presented in Tables 4 and 5. Also, the $\mathrm{R}^{2}$ of linear and exponential regressions are shown when significant $(P \leq 0.05)$. In Table 6 the Pearson correlations between volatile compounds, odours and TBARS values are shown. Finally, based in all the results, a proposal of eight volatile compounds as shelf-life markers in raw meat is discussed.

\subsection{Acids}

Carboxylic saturated fatty acids from C4-C10 were quantified and all of them, except decanoic acid, were affected by display in high oxygen MAP (Table 1). Three of them, pentanoic, hexanoic and heptanoic acids, increased more clearly with display time either exponentially and/or linearly (Tables 2 and 3). Furthermore, those three compounds were generally affected by the oxidative group and were highly correlated with TBARS 
analysis and rancid odour intensity (Tables 1-3 and 6). Hexanoic acid, together with butanoic and nonanoic acids, are usually raised in spoiled raw meat stored, imparting fatty, gammy, cheesy and dairy odours (Casaburi et al., 2015). However, in other studies using non-inoculated meat, but related to the effect of ageing/storage in raw/cooked meat, the results are controversial and sometimes acids have not even been reported (Gorraiz et al., 2002; Insausti et al., 2002; Ma et al., 2012; Meinert, Andersen, Bredie, Bjergegaard \& Aaslyng, 2007; Resconi et al., 2012). In one study, hexanoic acid was found in raw beef stored in MAP but not in vacuum conditions, and no statistical effect of storage time (10 vs 21 days) was observed (Saraiva et al., 2015). On the other hand, in a study with pork meat, butanoic and nonanoic acids decreased in raw meat refrigerated in oxygen permeable films for 10 days and hexanoic acid was only found in the cooked and refrigerated meat but not in the raw meat (Estévez et al., 2003).

With respect to pre-ageing 15 vs 22 days in vacuum packs, in our study the seven acids quantified had shown a direct and/or interactions effects, being the effect of ageing of higher importance compared to display time for nonanoic and decanoic acids (lower $P$, higher F values, Table 1). These two volatiles were generally higher in the samples aged for 15 days (Tables 2-3). The behaviour of the rest of acids was more erratic. Nevertheless, Watanabe et al. (2015) found no effect of ageing until 30 days in volatile fatty acids from cooked M. biceps femoris in beef.

Differences between studies could be related with different methodology approaches, i.e. SPME extractions are more sensitive to acids compared to dynamic headspace extraction (DHE) (Rivas-Cañedo, Juez-Ojeda, Nuñez \& Fernández-García, 2011), but also due to the complexity in the development of these compounds, which explains the high variability usually found. The acids in the meat can derive from several pathways, 
including enzymatic and chemical reactions and bacterial action, being the source lipids, aminoacids or carbohydrates (Resconi et al., 2013; Whitfield, 1998). At the same time, acids could be further degraded to other aroma compounds (Casaburi et al., 2015).

\subsection{Aldehydes and ketones}

The effect of display found in aldehydes and ketones is not surprising since they are major lipid oxidation products (Table 1) and MAP with high concentration of oxygen promotes oxidation. However, a high variability was generally found, as reported previously (Estévez et al., 2003) and this may explain the low $\mathrm{R}^{2}$ generally found when regression of carbonyl compounds throughout time of display were projected (Table 2). Saturated aldehydes have been previously described as affected by storage in raw beef packed with high oxygen, but alkenals and alkadienals had not been reported (Insausti et al., 2002). In our study three saturated aldehydes, seven alkenals and alkadienals and phenylacetaldehyde were quantified, and among them (E)-2-undecenal and 2-heptanone could be potential predictors of odour shelf-life as will be explained in section 3.6. Specifically, 2-heptanone has been already proposed as a candidate for the aroma differences between less or more oxidized cooked beef (Resconi et al., 2012) and had also shown an increment with storage time in raw meat (Estévez et al., 2003; Insausti et al., 2002), although the increase of 3-hydroxy-2-butanone was more pronounced in pork meat (Estévez et al., 2003).

Some aldehydes such as (E,E)-2,4-nonadienal, $(E)$-2-heptenal and (E)-2-nonenal were also influenced by ageing for 15 or 22 days (Table 1). Other authors have not found significant differences between day 2 to 30 in cooked beef due to a high variability of the data (Watanabe et al., 2015). 


\subsection{Esters}

Ethyl- hexanoate and ethyl- octanoate increased with display time in MAP and oxidative group (Tables 1-3) and they are between the esters of greater odour impact in raw meat, giving fruity off-odours (Casaburi et al., 2015). In general, esters derived from the esterification of alcohols and carboxylic acids are found in meat after microbial enzyme activity (Casaburi et al., 2015).

\subsection{Alcohols and 2-pentylfuran}

Alkylfurans and alcohols are mainly formed when aminoacids and ribose interacted in the lipid oxidation pathway; 2-pentylfuran, 1-octen-3-ol and 1-hexanol, for example, arise mainly from linoleic acid (Elmore, Campo, Enser \& Mottram, 2002; Van Ba, Amna \& Hwang, 2013). Since ageing increases the concentration of free aminoacids and sugars (Koutsidis et al., 2008), while lipid oxidation in the meat intensifies through the days in display in high oxygen packs, the rise of 2-pentylfuran and 1-hexanol caused by display time, oxidative group and ageing seems reasonable (Tables 1-3). Although this furan is higher when meat is cooked at high temperatures, it has been also reported in raw meat, but not affected by storage time (Estévez et al., 2003; Meinert et al., 2007; Soncin, Chiesa, Cantoni \& Biondi, 2007). In cooked meat, its concentration was reduced with the use of antioxidants and was related with off-flavour notes (Morán et al., 2013; Stetzer et al., 2008), but again no significant effect of storage has been observed (Estévez et al., 2003; Ma et al., 2012; Meinert et al., 2007; Stetzer et al., 2008; Watanabe et al., 2015).

The alcohol, 1-hexanol, followed a similar behaviour than pentylfuran, although its rate of formation was higher and in general more abundant (Tables 2-3). The alcohol can 
also be increased in stored meat due to the growth of natural spoilage bacteria (La Storia et al., 2012), giving pungent, ethereal, fuel oil, fruity, alcoholic and sweet with a green top notes (Casaburi et al., 2015). In other studies, 1-hexanol and 1-octen-3-ol seem to increase with storage time, but the effect is not clear enough (Estévez et al., 2003; Ma et al., 2012; Watanabe et al., 2015). In the present study, the behaviour of 1-octen-3-ol was not clear according to the factors studied.

\subsection{Odour characterisation}

Several interactions between the factors studied were found (ageing, display, oxidative group), thus, odours were analysed within ageing time and within oxidative group or display days (Tables 1, 4 and 5). In general, the intensity of the typical odour of raw beef decreased with ageing and display time (Tables 1, 4 and 5). The antioxidant capacity of the meat also showed a significant effect, since samples from the high oxidative group presented lower intensities of raw meat odour compared to the low and medium oxidative groups, especially in meat aged for 15 days. On the other hand, rancid odour intensity increased with the days of display, ageing time and oxidative group (Tables 1, 4 and 5). In the high oxidative samples, pre-aged for 15 days, from the 7th day, the rancid odour is strong (the mean value exceed 5 out of 10 , Table 4), as it happened in the medium oxidative samples aged for 22 days (Table 5). As expected, comparing all the descriptors used in this study, rancid odour was the best indicator of the odour changes through display time (generally regressions with higher $\mathrm{R}^{2}$, Tables 45) both. In another study assessing off-odour development in unaged raw meat (longissimus dorsi) displayed in $\mathrm{MAP}\left(60 \% \mathrm{O}_{2}, 30 \% \mathrm{CO}_{2}\right.$ and $\left.10 \% \mathrm{~N}_{2}\right)$, the odour 
shelf-life was around seven days for a rustic breed (Retinta) and 10-12 days in other five local Spanish beef breeds (Insausti, Beriain, Purroy, Alberti, Gorraiz \& Alzueta, 2001). In the less oxidized samples (display 0, aged 15 days, low and medium oxidative groups), after raw meat odour, sweet odour was the second most intense odour, but when odour is deteriorating other odours such as rancid, musty, sulphury and even cooked meat odour gained positions (Table 4). Dairy, sour-acid, old were other attributes found in oxidized samples by panellists. Metallic odour was in general a low intense odour, but also showed a diminution with the time on display, especially for the meat aged during 22 days (Table 5). In individual samples, other sweet/fruity intense odours were also described in a late stage probably due to esters caused by microbial spoilage (Casaburi et al., 2015). According to Schevey et al. (2013) fresh meat odour gives rise to sweetness, and finally rancidity takes over storage.

Regardless the ageing method, the intensity of off-odours (musty, sour, yeasty, putrid) in loins have been previously described to increase linearly from 14 to 49 days of ageing, but differences were substantially reduced when trimming discoloured, dehydrated or putrefied areas (Lepper-Blilie, Berg, Buchanan \& Berg, 2016). When cooked, differences in aged flavour were perceived with the period of ageing but did not necessarily indicated a loss of quality (Lepper-Blilie et al., 2016). Values higher than 2 mg malonaldehyde/kg muscle were obtained in the medium oxidative samples aged for 22 days, at day 9 of display and at day 7 in the high oxidative groups previously aged for 15 or 22 days. Therefore, unpleasant cooked flavour would be expected, as this value has been proposed as the limiting threshold for beef eating acceptability (Campo et al., 2006). 


\subsection{Potential shelf-life markers}

Eight volatile compounds (penta/hexa/heptanoic acids, 1-hexanol, (E)-2-undecenal, ethyl- octanoate, 2-heptanone and 2-pentylfuran) of raw meat in high oxygen MAP increased during display and were highly correlated with rancid odours and TBARS (Table 6). Therefore, they are proposed as shelf-life markers. Off-odour in the raw meat stored in high oxygen packs has been previously related with lipid oxidation (Insausti et al., 2001), but branched chain amino acids and pyruvate catabolism were more important than lipid oxidation in raw meat refrigerated in film (Estévez et al., 2003).

When regressions of the eight compounds throughout display time are compared, penta and hexanoic acids showed high $\mathrm{R}^{2}$, especially in the exponential regressions from all oxidative and ageing groups. Whereas 1-hexanol it is also an outstanding predictor of time in display for the 15 days aged meat, ethyl- octanoate and 2-pentylfuran are for the 22 days aged meat, considering all oxidative groups, which may represent better commercial situations. The five mentioned compounds were also abundant and with higher rates of increase with display time. In refrigerated cooked meat, mainly hexanal, but also other saturated aldehydes have been found to be the odorous compounds more abundant and with higher rate of increase (Drumm \& Spanier, 1991) and therefore indicators of warmed over flavour. Finally, comparing the oxidative groups, no particular compound/s seems to predict changes over display only in one of the three groups studied, which means that the differences between the groups are mainly quantitative.

In Figures 1-5 of the supplementary material the increase of these five compounds through display are represented in box plots. It is possible to visualize the high variability of the compounds in the headspace of raw meat, which was higher in meat 
exposed to MAP compared to meat vacuum packed. High variation in the generation of volatile compounds from meat have been also found previously (Estévez et al., 2003; Watanabe et al., 2015), and reasons are several, due to the complexity in the formation of the compounds and the interactions that could take place.

\section{ASSOCIATED CONTENT}

\section{Supplementary material}

Box plots for five compounds proposed as shelf-life markers of knuckle steaks.

\section{CONCLUSIONS}

In the raw knuckle, around five days of odour shelf-life is expected in high oxidative samples displayed in high oxygen atmosphere packaging and previously aged during 22 days. On the other hand, low oxidative meat aged for 15 days could be displayed during nine days, without severe alteration of the odour. Those results indicate the high importance of controlling the balance between anti- and pro-oxidants in the meat.

The odour shelf-life of the meat could be predicted by the analysis of volatile compounds thorough SPME-GCMS analysis. Results have shown that the most sensitive and precise predictors of display in all oxidative groups were 1-hexanol for meat pre-aged during 15 days, ethyl- octanoate and 2-pentylfuran for meat pre-aged 22 days, and penta/ and hexanoic acids for both ageing times.

\section{ACKNOWLEDGEMENTS}


V.C. Resconi was supported by a contract from the Juan de la Cierva-Incorporación Program (Ministerio de Economía y Competitividad), Spain. D. Magalhaes was supported by a scholarship from $\mathrm{CNPq}$ (Conselho Nacional de desenvolvimento científico e tecnológico), Brazil. Authors thanks J. Pomed, M. Barahona and J. L. Olleta for their technical assistance. Funding from Diputación General de Aragón (T53) and Fondo Social Europeo is acknowledged.

\section{REFERENCES}

Aaslyng, M. D., Tørngren, M. A., \& Madsen, N. T. (2010). Scandinavian consumer preference for beef steaks packed with or without oxygen. Meat Science, 85(3), 519-524.

Campo, M. M., Nute, G. R., Hughes, S. I., Enser, M., Wood, J. D., \& Richardson, R. I. (2006). Flavour perception of oxidation in beef. Meat Science, 72(2), 303-311.

Casaburi, A., Piombino, P., Nychas, G.-J., Villani, F., \& Ercolini, D. (2015). Bacterial populations and the volatilome associated to meat spoilage. Food Microbiology, 45, Part A, 83-102.

Colle, M. J., Richard, R. P., Killinger, K. M., Bohlscheid, J. C., Gray, A. R., Loucks, W. I., Day, R. N., Cochran, A. S., Nasados, J. A., \& Doumit, M. E. (2015). Influence of extended aging on beef quality characteristics and sensory perception of steaks from the gluteus medius and longissimus lumborum. Meat Science, 110, 32-39.

Drumm, T. D., \& Spanier, A. M. (1991). Changes in the content of lipid autoxidation and sulfur-containing compounds in cooked beef during storage. Journal of Agricultural and Food Chemistry, 39(2), 336-343.

Elmore, J. S., Campo, M. M., Enser, M., \& Mottram, D. S. (2002). Effect of Lipid Composition on Meat-like Model Systems Containing Cysteine, Ribose, and Polyunsaturated Fatty Acids. Journal of Agricultural and Food Chemistry, 50(5), 1126-1132. 
Estévez, M., Morcuende, D., Ventanas, S., \& Cava, R. (2003). Analysis of Volatiles in Meat from Iberian Pigs and Lean Pigs after Refrigeration and Cooking by Using SPME-GC-MS. Journal of Agricultural and Food Chemistry, 51(11), 3429-3435.

Gorraiz, C., Beriain, M. J., Chasco, J., \& Insausti, K. (2002). Effect of Aging Time on Volatile Compounds, Odor, and Flavor of Cooked Beef from Pirenaica and Friesian Bulls and Heifers. Journal of Food Science, 67(3), 916-922.

Insausti, K., Beriain, M. J., Gorraiz, C., \& Purroy, A. (2002). Volatile Compounds of Raw Beef from 5 Local Spanish Cattle Breeds Stored Under Modified Atmosphere. Journal of Food Science, 67(4), 1580-1589.

Insausti, K., Beriain, M. J., Purroy, A., Alberti, P., Gorraiz, C., \& Alzueta, M. J. (2001). Shelf life of beef from local Spanish cattle breeds stored under modified atmosphere. Meat Science, 57(3), 273-281.

Koutsidis, G., Elmore, J. S., Oruna-Concha, M. J., Campo, M. M., Wood, J. D., \& Mottram, D. S. (2008). Water-soluble precursors of beef flavour. Part II: Effect of post-mortem conditioning. Meat Science, 79(2), 270-277.

La Storia, A., Ferrocino, I., Torrieri, E., Di Monaco, R., Mauriello, G., Villani, F., \& Ercolini, D. (2012). A combination of modified atmosphere and antimicrobial packaging to extend the shelf-life of beefsteaks stored at chill temperature. International Journal of Food Microbiology, 158(3), 186-194.

Lepper-Blilie, A. N., Berg, E. P., Buchanan, D. S., \& Berg, P. T. (2016). Effects of post-mortem aging time and type of aging on palatability of low marbled beef loins. Meat Science, 112, 63-68.

Ma, Q. L., Hamid, N., Bekhit, A. E. D., Robertson, J., \& Law, T. F. (2012). Evaluation of pre-rigor injection of beef with proteases on cooked meat volatile profile after 1 day and 21 days post-mortem storage. Meat Science, 92(4), 430-439.

Meinert, L., Andersen, L. T., Bredie, W. L. P., Bjergegaard, C., \& Aaslyng, M. D. (2007). Chemical and sensory characterisation of pan-fried pork flavour: Interactions between raw meat quality, ageing and frying temperature. Meat Science, 75(2), 229-242.

Meinert, L., Tikk, K., Tikk, M., Brockhoff, P. B., Bredie, W. L. P., Bjergegaard, C., \& Aaslyng, M. D. (2009). Flavour development in pork. Influence of flavour precursor concentrations in longissimus dorsi from pigs with different raw meat qualities. Meat Science, 81(1), 255-262. 
Monsón, F., Sañudo, C., \& Sierra, I. (2005). Influence of breed and ageing time on the sensory meat quality and consumer acceptability in intensively reared beef. Meat Science, 71(3), 471-479.

Morán, L., Giráldez, F. J., Panseri, S., Aldai, N., Jordán, M. J., Chiesa, L. M., \& Andrés, S. (2013). Effect of dietary carnosic acid on the fatty acid profile and flavour stability of meat from fattening lambs. Food Chemistry, 138(4), 24072414.

O'Quinn, T. G., Woerner, D. R., Engle, T. E., Chapman, P. L., Legako, J. F., Brooks, J. C., Belk, K. E., \& Tatum, J. D. (2016). Identifying consumer preferences for specific beef flavor characteristics in relation to cattle production and postmortem processing parameters. Meat Science, 112, 90-102.

Panseri, S., Chiesa, L. M., Biondi, P. A., Rusconi, M., Giacobbo, F., Padovani, E., \& Mariani, M. (2015). Irradiated ground beef patties: Dose and dose-age estimation by volatile compounds measurement. Food Control, 50, 521-529.

Pérez-Juan, M., Realini, C. E., Barahona, M., Sarriés, M. V., del Mar Campo, M., Beriain, M. J., Vitale, M., Gil, M., \& Albertí, P. (2014). Effects of Enrichment with Polyunsaturated Fatty Acids (Omega-3 and Conjugated Linoleic Acid) on Consumer Liking of Beef Aged for 7 or $21 \mathrm{~d}$ Evaluated at Different Locations. Journal of Food Science, 79(11), S2377-S2382.

Pérez, R. A., Rojo, M. D., González, G., \& Lorenzo, C. D. (2008). Solid-phase microextraction for the determination of volatile compounds in the spoilage of raw ground beef. JOurnal of AOAC International, 91(6), 1409-1415.

Pfalzgraf, A., Frigg, M., \& Steinhart, H. (1995). Alpha-tocopherol Contents and Lipid Oxidation in Pork Muscle and Adipose Tissue during Storage. Journal of Agricultural and Food Chemistry, 43(5), 1339-1342.

Resconi, V., Escudero, A., \& Campo, M. (2013). The Development of Aromas in Ruminant Meat. Molecules, 18(6), 6748.

Resconi, V. C., Escudero, A., Beltrán, J. A., Olleta, J. L., Sañudo, C., \& Campo, M. M. (2012). Color, lipid oxidation, sensory quality and aroma compounds of beef steaks displayed under different levels of oxygen in a modified atmosphere package. Journal of Food Science, 77(1), S10-18.

Rivas-Cañedo, A., Apeleo, E., Muiño, I., Pérez, C., Lauzurica, S., PérezSantaescolástica, C., Díaz, M. T., Cañque, V., \& de la Fuente, J. (2013). Effect of 
dietary supplementation with either red wine extract or vitamin $\mathrm{E}$ on the volatile profile of lamb meat fed with omega-3 sources. Meat Science, 93(2), 178-186.

Rivas-Cañedo, A., Juez-Ojeda, C., Nuñez, M., \& Fernández-García, E. (2011). Volatile compounds in ground beef subjected to high pressure processing: A comparison of dynamic headspace and solid-phase microextraction. Food Chemistry, 124(3), 1201-1207.

Rota, V., \& Schieberle, P. (2005). Changes in Key Odorants of Sheep Meat Induced by Cooking. Food Lipids, vol. 920 (pp. 73-83). Washington, DC (USA): American Chemical Society.

Saraiva, C., Oliveira, I., Silva, J. A., Martins, C., Ventanas, J., \& García, C. (2015). Implementation of multivariate techniques for the selection of volatile compounds as indicators of sensory quality of raw beef. Journal of Food Science and Technology, 52(6), 3887-3898.

Schevey, C. T., Toshkov, S., \& Brewer, M. S. (2013). Effect of Natural Antioxidants, Irradiation, and Cooking on Lipid Oxidation in Refrigerated, Salted Ground Beef Patties. Journal of Food Science, 78(11), S1793-S1799.

Schindler, S., Krings, U., Berger, R. G., \& Orlien, V. (2010). Aroma development in high pressure treated beef and chicken meat compared to raw and heat treated. Meat Science, 86(2), 317-323.

Smith, R. D., Nicholson, K. L., Nicholson, J. D. W., Harris, K. B., Miller, R. K., Griffin, D. B., \& Savell, J. W. (2008). Dry versus wet aging of beef: Retail cutting yields and consumer palatability evaluations of steaks from US Choice and US Select short loins. Meat Science, 79(4), 631-639.

Soncin, S., Chiesa, L. M., Cantoni, C., \& Biondi, P. A. (2007). Preliminary study of the volatile fraction in the raw meat of pork, duck and goose. Journal of Food Composition and Analysis, 20(5), 436-439.

Stetzer, A. J., Cadwallader, K., Singh, T. K., McKeith, F. K., \& Brewer, M. S. (2008). Effect of enhancement and ageing on flavor and volatile compounds in various beef muscles. Meat Science, 79(1), 13-19.

Thompson, J. (2002). Managing meat tenderness. Meat Science, 62(3), 295-308.

Van Ba, H., Amna, T., \& Hwang, I. (2013). Significant influence of particular unsaturated fatty acids and $\mathrm{pH}$ on the volatile compounds in meat-like model systems. Meat Science, 94(4), 480-488. 
Watanabe, A., Kamada, G., Imanari, M., Shiba, N., Yonai, M., \& Muramoto, T. (2015). Effect of aging on volatile compounds in cooked beef. Meat Science, 107, 12-19.

Whitfield, F. B. (1998). Microbiology of food taints. International Journal of Food Sciences and Technology, 33, 31-51. 
Table 1. F value and significance of ageing (15 or $22 \mathrm{~d}$ ), display time $(0,5,7$ or $9 \mathrm{~d})$ and oxidative group ${ }^{1}$ (low, medium or high) effects and their interactions in volatile compounds analysed by SPME-GCMS, odour intensity and TBARS value from raw knuckle steaks

\begin{tabular}{|c|c|c|c|c|c|c|c|c|c|}
\hline & LRI & Quan ion & Ageing & Display & $\begin{array}{l}\text { Oxidative } \\
\text { Group }\end{array}$ & $A \times D$ & $A \times O G$ & $\mathrm{D} \times \mathrm{OG}$ & $A \times D \times O G$ \\
\hline \multicolumn{10}{|l|}{ Acids } \\
\hline Butanoic acid & 1632 & 60 & ns & $5.84 * * *$ & ns & $5.29 * * *$ & $3.47^{*}$ & $3.75 * * *$ & ns \\
\hline Pentanoic acid & 1744 & 60 & $34.3 * * *$ & $124 * * *$ & $45.2 * * *$ & $5.27 * * *$ & ns & $4.15^{* * *}$ & $2.93 * *$ \\
\hline Hexanoic acid & 1851 & 60 & $4.34 *$ & $155^{* * *}$ & $35.0 * * *$ & ns & $4.39 *$ & $7.02 * * *$ & $3.42 * *$ \\
\hline Heptanoic acid & 1975 & 60 & $6.46 *$ & $85.7 * * *$ & $7.76 * * *$ & $5.84 * * *$ & $3.69 *$ & $2.17^{*}$ & $3.16^{* *}$ \\
\hline Octanoic acid & 2051 & 60 & ns & $11.2 * * *$ & ns & $11.4^{* * *}$ & ns & ns & $2.51 *$ \\
\hline Nonanoic acid & 2116 & 60 & $17.0 * * *$ & $4.87 * *$ & ns & $4.62 * *$ & ns & ns & $3.16 * *$ \\
\hline Decanoic acid & 2200 & 60 & $28.0 * * *$ & ns & ns & ns & $3.88^{*}$ & ns & ns \\
\hline \multicolumn{10}{|l|}{ Alcohols } \\
\hline 1-Hexanol & 1359 & 69 & $10.9 * * *$ & $84.1 * * *$ & $81.8 * * *$ & ns & $3.45 *$ & $8.35 * * *$ & $3.08 * *$ \\
\hline 1-Octen-3-ol & 1449 & 57 & ns & $15.1 * * *$ & $5.13 * *$ & $15.0 * * *$ & ns & ns & $3.72 * * *$ \\
\hline \multicolumn{10}{|l|}{ Aldehydes } \\
\hline Hexanal & 1052 & 57 & ns & ns & ns & $4.74 * *$ & ns & ns & ns \\
\hline Heptanal & 1188 & 71 & ns & $6.85 * * *$ & $6.31 * *$ & ns & $9.26 * * *$ & $3.03 * *$ & ns \\
\hline
\end{tabular}




\begin{tabular}{|c|c|c|c|c|c|c|c|c|c|}
\hline Nonanal & 1402 & $98+120$ & ns & $2.98 *$ & ns & ns & ns & ns & ns \\
\hline (E)-2-Heptenal & 1344 & 97 & $9.98 * *$ & $10.3^{* * *}$ & $7.71 * * *$ & ns & ns & ns & $2.44^{*}$ \\
\hline (Z)-2-Octenal & 1420 & 83 & $4.37^{*}$ & $21.8 * * *$ & $13.9 * * *$ & ns & ns & ns & $2.14^{*}$ \\
\hline (E)-2-Nonenal & 1562 & 93 & $9.64 * *$ & $10.6 * * *$ & $7.06 * * *$ & $2.80 *$ & ns & ns & $2.94 * *$ \\
\hline$(E, E)-2,4-N o n a d i e n a l$ & 1741 & 81 & $7.11 * *$ & $3.50 *$ & $4.02 *$ & ns & ns & ns & ns \\
\hline (E)-2-Undecenal & 1781 & 83 & ns & $49.5^{* * *}$ & $45.8 * * *$ & ns & $4.10 *$ & $3.91 * * *$ & ns \\
\hline$(E, Z)-2,4$-Decadienal & 1799 & 81 & ns & $15.8^{* * *}$ & ns & ns & ns & ns & $2.58^{*}$ \\
\hline$(E, E)-2,4-D e c a d i e n a l$ & 1854 & 81 & $5.37^{*}$ & $21.1 * * *$ & $10.4^{* * *}$ & ns & ns & ns & $2.61 *$ \\
\hline Phenylacetaldehyde & 1681 & $91+120$ & $3.88^{*}$ & $3.36^{*}$ & ns & ns & ns & ns & ns \\
\hline \multicolumn{10}{|l|}{ Esters } \\
\hline Ethyl-hexanoate & 1236 & 88 & ns & $44.5^{* * *}$ & $15.0 * * *$ & $3.44 *$ & $9.68 * * *$ & $2.72 *$ & $6.37^{* * *}$ \\
\hline Ethyl-octanoate & 1438 & 88 & ns & $115 * * *$ & $36.5^{* * *}$ & ns & $23.6 * * *$ & $2.17^{*}$ & $2.62 *$ \\
\hline \multicolumn{10}{|l|}{ Ketones } \\
\hline 2-Butanone & 668 & 72 & ns & $3.51 *$ & ns & ns & ns & ns & ns \\
\hline 2-Heptanone & 1192 & 99 & $3.93 *$ & $58.4^{* * *}$ & $10.4^{* * *}$ & ns & ns & ns & ns \\
\hline 3-Octanone & 1265 & 99 & ns & $20.3 * * *$ & $3.30 *$ & ns & $6.76 * * *$ & $2.96 * *$ & ns \\
\hline
\end{tabular}




\begin{tabular}{|c|c|c|c|c|c|c|c|c|c|}
\hline 2-Octanone & 1293 & 58 & ns & $35.8^{* * *}$ & $5.55^{* *}$ & ns & $7.63 * *$ & ns & ns \\
\hline 2-Nonanone & 1400 & 142 & ns & $16.3 * * *$ & ns & $3.49 *$ & $3.28 *$ & ns & $2.88^{* *}$ \\
\hline 1-Octen-3-one & 1311 & 70 & ns & $20.7^{* * *}$ & $7.85 * * *$ & $4.59 * *$ & ns & ns & $2.52 *$ \\
\hline 3-Octen-2-one & 1427 & 111 & ns & $8.09 * * *$ & $3.06 *$ & $2.96 *$ & ns & ns & ns \\
\hline 3-Nonen-2-one & 1535 & 125 & ns & $4.77^{* *}$ & ns & ns & ns & ns & ns \\
\hline 2,3-Octanedione & 1332 & 99 & ns & $5.33 * * *$ & ns & $5.62 * * *$ & ns & ns & ns \\
\hline \multicolumn{10}{|l|}{ Others } \\
\hline 2-Pentylfuran & 1235 & 138 & $11.0 * *$ & $38.7^{* * *}$ & $33.5^{* * *}$ & ns & ns & $4.32 * * *$ & ns \\
\hline \multicolumn{10}{|l|}{ Odour intensity } \\
\hline Raw meat odour & & & $84.7 * * *$ & $57.9^{* * *}$ & $22.9 * * *$ & $3.24 *$ & $5.02 * *$ & ns & $3.19 * *$ \\
\hline Rancid odour & & & $54.4 * * *$ & $184 * * *$ & $70.4^{* * *}$ & ns & ns & $5.29 * * *$ & ns \\
\hline Metallic odour & & & ns & $17.8 * * *$ & $4.60 *$ & $3.18 *$ & ns & ns & $2.96 * *$ \\
\hline Sweet odour & & & $23.1 * * *$ & $14.4^{* * *}$ & ns & $2.87^{*}$ & ns & ns & $2.54 *$ \\
\hline Musty odour & & & ns & $39.2 * * *$ & $14.0 * * *$ & $12.6^{* * *}$ & $13.4^{* * *}$ & ns & $3.54^{* *}$ \\
\hline Cooked meat odour & & & $4.56 *$ & $51.1^{* * *}$ & ns & $6.53 * * *$ & $3.77^{*}$ & $3.31 * *$ & $2.13 *$ \\
\hline Sulphury odour & & & $11.6 * * *$ & $18.8 * * *$ & $7.37^{* * *}$ & ns & $3.66 *$ & ns & $2.62 *$ \\
\hline
\end{tabular}




\begin{tabular}{llllllll}
\hline TBARS value & $20.5 * * *$ & $210 * * *$ & $146 * * *$ & $4.46 * *$ & $\mathrm{~ns}$ & $20.5 * * *$ \\
\hline
\end{tabular}

${ }^{1}$ Low, medium and high oxidative groups, when reached $<1,1-2$ or $>2 \mathrm{mg} \mathrm{MDA} / \mathrm{kg}$ muscle (TBARS values), respectively, on day 9 of display in samples aged 15 days. LRI: linear retention index calculated for DB-WAXETR capillary column. A: aging. D: display. OG: oxidative group. Quan ion: $\mathrm{m} / \mathrm{z}$ used for quantification. ns: $P>0.05, *: P \leq 0.05$, $* *: P \leq 0.01, * * * P \leq 0.001$. 
Table 2. Mean and standard deviation for volatile compounds ( $\mu \mathrm{g} / \mathrm{g}$ ) of knuckle steaks aged for 15 days under vacuum conditions and displayed in modified atmosphere packaging $\left(0,5,7\right.$ or 9 days), according oxidative group ${ }^{1}$.

\begin{tabular}{|c|c|c|c|c|c|c|c|c|}
\hline \multirow{2}{*}{ Compound } & \multirow{2}{*}{$\begin{array}{l}\text { Oxidative } \\
\text { group }\end{array}$} & \multicolumn{4}{|c|}{ Display (days) } & \multirow{2}{*}{$\begin{array}{c}P \\
\text { display }\end{array}$} & \multicolumn{2}{|c|}{ Regressions $^{3}$} \\
\hline & & 0 & 5 & 7 & 9 & & Linear & Exponential \\
\hline \multirow[t]{3}{*}{ Butanoic acid } & Low & $17.9 \pm 14.8$ & $18.6 \pm 17.6$ & $26.5 \pm 10.5^{x}$ & $25.5 \pm 12.1$ & 0.193 & & 0.093 \\
\hline & Medium & $9.76 \pm 7.68^{b}$ & $10.9 \pm 12.9^{b}$ & $22.9 \pm 9.3^{\mathrm{aXY}}$ & $24.1 \pm 9.2^{a}$ & $<0.001$ & 0.240 & 0.216 \\
\hline & High & $18.4 \pm 10.1$ & $16.7 \pm 19.8$ & $17.7 \pm 5.0^{Y}$ & $20.9 \pm 6.7$ & 0.772 & & \\
\hline \multicolumn{2}{|c|}{$P$ oxidative group } & 0.067 & 0.437 & 0.018 & 0.363 & & & \\
\hline \multirow[t]{3}{*}{ Pentanoic acid } & Low & $1.31 \pm 0.95^{c}$ & $2.28 \pm 1.37^{b c}$ & $3.42 \pm 1.49 \mathrm{abY}$ & $4.44 \pm 1.69 \mathrm{aY}$ & $<0.001$ & 0.398 & 0.462 \\
\hline & Medium & $0.825 \pm 0.514$ & $2.22 \pm 1.93^{b}$ & $5.54 \pm 1.39$ ax & $6.53 \pm 1.84^{\mathrm{aY}}$ & $<0.001$ & 0.628 & 0.633 \\
\hline & High & ${ }^{b} 1.57 \pm 0.97^{c}$ & $4.82 \pm 5.00 \mathrm{bc}$ & $6.64 \pm 2.04 \mathrm{bx}$ & $12.2 \pm 4.8^{a x}$ & $<0.001$ & .467 & 0.646 \\
\hline \multicolumn{2}{|c|}{$P$ oxidative group } & 0.052 & 0.042 & $<0.001$ & $<0.001$ & & & \\
\hline \multirow[t]{3}{*}{ Hexanoic acid } & Low & $14.0 \pm 10.3^{c}$ & $45.3 \pm 24.3^{b Y}$ & $71.4 \pm 40.1^{\mathrm{abY}}$ & $89.6 \pm 35.3^{a z}$ & $<0.001$ & 0.481 & 0.619 \\
\hline & Medium & $9.42 \pm 6.28^{c}$ & $56.3 \pm 39.9^{b Y}$ & $133 \pm 24^{a x}$ & $144 \pm 24^{\mathrm{aY}}$ & $<0.001$ & 0.753 & 0.802 \\
\hline & High & $19.7 \pm 17.2^{b}$ & $125 \pm 121^{a x}$ & $142 \pm 35^{a x}$ & $177 \pm 36^{a x}$ & $<0.001$ & .447 & 0.750 \\
\hline \multicolumn{2}{|c|}{$P$ oxidative group } & 0.073 & 0.009 & $<0.001$ & $<0.001$ & & & \\
\hline \multirow[t]{3}{*}{ Heptanoic acid } & Low & $1.33 \pm 0.53^{b}$ & $1.98 \pm 1.14^{b X Y}$ & $2.04 \pm 1.02^{b Y}$ & $3.29 \pm 1.49 \mathrm{ar}$ & $<0.001$ & 0.241 & 0.225 \\
\hline & Medium & $1.21 \pm 0.91^{b}$ & $1.73 \pm 0.88^{b Y}$ & $3.29 \pm 1.14^{\mathrm{ax}}$ & $3.89 \pm 2.00^{\mathrm{aY}}$ & $<0.001$ & 0.366 & \\
\hline & High & $1.05 \pm 0.81^{c}$ & $3.26 \pm 2.27^{b x}$ & $3.29 \pm 1.17^{b x}$ & $5.76 \pm 2.02 \mathrm{ax}$ & $<0.001$ & .455 & 0.642 \\
\hline \multicolumn{2}{|c|}{$P$ oxidative group } & 0.575 & 0.018 & 0.003 & 0.001 & & & \\
\hline \multirow[t]{3}{*}{ Octanoic acid } & Low & $4.87 \pm 2.28 \mathrm{ab}$ & $4.63 \pm 2.57^{\mathrm{ab}}$ & $3.93 \pm 1.97^{b Y}$ & $6.77 \pm 3.26^{a}$ & 0.019 & & \\
\hline & Medium & $4.43 \pm 2.83$ & $3.68 \pm 1.82$ & $6.19 \pm 2.80^{x}$ & $6.59 \pm 4.93$ & 0.055 & & 0.081 \\
\hline & High & $3.49 \pm 2.15^{b}$ & $5.04 \pm 2.65^{\mathrm{ab}}$ & $4.18 \pm 2.01^{\mathrm{abY}}$ & $5.69 \pm 2.56^{a}$ & 0.044 & 0.078 & 0.135 \\
\hline \multicolumn{2}{|c|}{$P$ oxidative group } & 0.255 & 0.271 & 0.016 & 0.662 & & & \\
\hline \multirow[t]{3}{*}{ Nonanoic acid } & Low & $13.9 \pm 6.2$ & $16.2 \pm 15.2$ & $10.1 \pm 9.1$ & $17.6 \pm 11.1$ & 0.242 & & \\
\hline & Medium & $16.4 \pm 11.5$ & $11.3 \pm 6.2$ & $15.9 \pm 10.7$ & $17.2 \pm 21.0$ & 0.635 & & \\
\hline & High & $8.83 \pm 7.92$ & $16.3 \pm 10.5$ & $11.1 \pm 8.8$ & $8.71 \pm 7.65$ & 0.049 & & \\
\hline
\end{tabular}


$P$ oxidative group

Decanoic acid

Low

Medium

High

1-Hexanol

1-Octen-3-ol

$P$ oxidative group

Low
Medium
High

High

Low

Medium

High

$P$ oxidative group

Hexanal

Low

Medium

High

$P$ oxidative group Heptanal

Low

Medium

High

$P$ oxidative group

Nonanal

Low

Medium

High

$P$ oxidative group

(E)-2-Heptenal

Low

Medium

High

$P$ oxidative group
0.053

$0.733 \pm 0.257$

$0.784 \pm 0.521$

$0.605 \pm 0.250$

0.350

$2.60 \pm 3.90$ br

$6.39 \pm 12.84 \mathrm{br}$

$63.8 \pm 107.1^{c x}$

0.014

$0.120 \pm 0.134$ br

$0.346 \pm 0.443$ bXY

$0.455 \pm 0.324 x$

0.015

$2.69 \pm 4.18$

$36.2 \pm 133.6$

$25.4 \pm 61.8$

0.521

$5.29 \pm 4.81$

$5.21 \pm 4.37^{b}$

$19.8 \pm 31.9^{b}$

0.055

$1.85 \pm 3.52$

$3.57 \pm 12.33$

$5.07 \pm 12.42$

0.6700 .012

$\pm 0.025^{b}$

$0.077 \pm 0.250$

$0.138 \pm 0.291^{b}$

0.281
0.390

$0.880 \pm 0.498$

$0.643 \pm 0.327$

$0.777 \pm 0.540$

0.376

$24.36 \pm 23.00$

by $85.9 \pm 87.6$

bXy $439 \pm 699$ bcx

0.0140 .169

$\pm 0.153^{\mathrm{b}}$

$0.331 \pm 0.422$

${ }^{\mathrm{b}} 0.424 \pm 0.348$

0.088

$9.41 \pm 15.79 \mathrm{XY}$

$5.32 \pm 7.30^{\mathrm{Y}}$

$20.2 \pm 17.2^{x}$

0.014

$9.44 \pm 13.63^{\mathrm{Y}}$

$29.0 \pm 44.5^{a b X Y}$

$60.3 \pm 52.5^{\text {ax }}$

0.003

$2.24 \pm 1.56$

$2.55 \pm 3.76$

$4.80 \pm 4.56$

0.089

$0.339 \pm 0.514^{a}$

$0.220 \pm 0.244$

$0.795 \pm 1.029^{a}$

0.054
0.203

0.137

$0.661 \pm 0.276$

$0.736 \pm 0.179$

$0.593 \pm 0.187$

0.194

$99.5 \pm 102.3 \mathrm{az}$

$332 \pm 121$ ar

$841 \pm 365$ bx

$<0.001$

$0.672 \pm 0.391^{a}$

$0.944 \pm 0.640^{\mathrm{a}}$

$0.672 \pm 0.481$

0.244

$3.85 \pm 6.27$

$22.5 \pm 29.8$

$28.7 \pm 45.0$

0.079

$8.92 \pm 9.89^{\mathrm{r}}$

$50.7 \pm 36.7^{\mathrm{ax}}$

$33.2 \pm 33.2$ abXY

0.001

$0.565 \pm 0.573$

$7.93 \pm 21.98$

$19.4 \pm 48.4$

0.231

$0.054 \pm 0.081^{\text {by }}$

$0.273 \pm 0.318^{x}$

$0.409 \pm 0.276$ abx

0.001

0.453

0.017

0.751

0.135

0.894
$0.758+0.234$

$0.710 \pm 0.443$

$0.622 \pm 0.231$

$149 \pm 114$ ar

$440 \pm 258$ aY

$1328 \pm 552$ ax

$<0.001$

$0.329 \pm 0.410$ br

$0.508 \pm 0.338$ abXY

$0.815 \pm 0.605^{x}$

$33.8 \pm 89.9$

$30.5 \pm 33.4$

$49.9 \pm 92.5$

$11.6 \pm 13.2$

$28.7 \pm 35.5^{\mathrm{ab}}$

$30.8 \pm 33.7^{\text {ab }}$

$5.31 \pm 8.97$

$5.61 \pm 8.72$

$4.36 \pm 5.50$

$0.188 \pm 0.182^{\mathrm{abr}} \quad 0.006$

$0.240 \pm 0.160^{Y} \quad 0.155$

$0.831 \pm 0.427$ ax

0.002

0.075

$<0.001$
0.725

0.775

0.674

0.261 


\begin{tabular}{|c|c|c|c|c|c|c|c|}
\hline \multirow[t]{3}{*}{ (Z)-2-Octenal } & Low & $0.014 \pm 0.032$ & $0.166 \pm 0.293$ & $0.081 \pm 0.119^{Y}$ & $0.099 \pm 0.085^{Y}$ & 0.087 & \\
\hline & Medium & $0.032 \pm 0.088^{b}$ & $0.137 \pm 0.075^{\mathrm{ab}}$ & $0.206 \pm 0.127^{a x}$ & $0.265 \pm 0.207^{\mathrm{ax}}$ & $<0.001$ & 0.305 \\
\hline & High & $0.061 \pm 0.096^{b}$ & $0.437 \pm 0.521^{a}$ & $0.223 \pm 0.121 \mathrm{abx}$ & $0.411 \pm 0.229 \mathrm{ax}$ & 0.001 & 0.120 \\
\hline \multicolumn{2}{|c|}{ P oxidative group } & 0.233 & 0.037 & 0.003 & $<0.001$ & & \\
\hline \multirow[t]{3}{*}{ (E)-2-Nonenal } & Low & $0.040 \pm 0.057^{b}$ & $0.208 \pm 0.254^{\mathrm{aXY}}$ & $0.076 \pm 0.127^{\mathrm{ab}}$ & $0.114 \pm 0.110^{a b y}$ & 0.021 & \\
\hline & Medium & $0.098 \pm 0.281$ & $0.105 \pm 0.101^{Y}$ & $0.198 \pm 0.247$ & $0.120 \pm 0.120^{Y}$ & 0.514 & \\
\hline & High & $0.095 \pm 0.169^{b}$ & $0.358 \pm 0.389 \mathrm{ax}$ & $0.168 \pm 0.140^{a b}$ & $0.376 \pm 0.274^{\mathrm{ax}}$ & 0.004 & 0.088 \\
\hline \multicolumn{2}{|c|}{$P$ oxidative group } & 0.629 & 0.045 & 0.145 & $<0.001$ & & \\
\hline \multirow[t]{3}{*}{$(E, E)-2,4-$ Nonadienal } & Low & $0.011 \pm 0.046$ & $0.339 \pm 0.647^{X Y}$ & $0.055 \pm 0.064^{Y}$ & $0.477 \pm 1.01^{x}$ & 0.094 & \\
\hline & Medium & $0.267 \pm 1.034$ & $0.143 \pm 0.168^{Y}$ & $0.344 \pm 0.410^{Y}$ & $0.439 \pm 0.335^{x}$ & 0.567 & \\
\hline & High & $0.066 \pm 0.196^{b}$ & $0.864 \pm 0.968^{b x}$ & $0.709 \pm 0.496 \mathrm{bx}$ & $1.95 \pm 1.62^{\mathrm{ar}}$ & $<0.001$ & 0.263 \\
\hline \multicolumn{2}{|c|}{$P$ oxidative group } & 0.454 & 0.014 & $<0.001$ & $<0.001$ & & \\
\hline \multirow[t]{3}{*}{ (E)-2-Undecenal } & Low & $0.105 \pm 0.161^{b \gamma}$ & $1.44 \pm 1.21^{\mathrm{ar}}$ & $1.07 \pm 0.66^{a z}$ & $1.20 \pm 0.50 \mathrm{az}$ & $<0.001$ & 0.217 \\
\hline & Medium & $0.286 \pm 0.573^{b X Y}$ & $1.79 \pm 1.08 \mathrm{aXY}$ & $2.21 \pm 0.59$ ar & $2.43 \pm 0.82^{\mathrm{ar}}$ & $<0.001$ & 0.528 \\
\hline & High & $0.771 \pm 1.019 \mathrm{bx}$ & $4.70 \pm 5.49$ ax & $3.80 \pm 1.36$ ax & $4.31 \pm 1.31$ ax & 0.001 & 0.163 \\
\hline \multicolumn{2}{|c|}{ P oxidative group } & 0.023 & 0.015 & $<0.001$ & $<0.001$ & & \\
\hline \multirow[t]{3}{*}{$(E, Z)-2,4-D e c a d i e n a l$} & Low & $0.029 \pm 0.070$ & $2.06 \pm 5.02$ & $0.089 \pm 0.100^{Y}$ & $0.535 \pm 0.786$ & 0.095 & \\
\hline & Medium & $0.330 \pm 0.954$ & $0.555 \pm 0.726$ & $0.550 \pm 0.641^{x}$ & $0.842 \pm 1.056$ & 0.451 & \\
\hline & High & $0.201 \pm 0.401^{b}$ & $2.05 \pm 1.93^{\mathrm{a}}$ & $0.508 \pm 0.252^{b x}$ & $0.890 \pm 1.082^{b}$ & $<0.001$ & \\
\hline \multicolumn{2}{|c|}{$P$ oxidative group } & 0.364 & 0.318 & 0.003 & 0.544 & & \\
\hline \multirow[t]{3}{*}{$(E, E)-2,4$-Decadienal } & Low & $0.049 \pm 0.156$ & $6.21 \pm 14.80$ & $0.992 \pm 1.189^{z}$ & $2.85 \pm 2.42^{Y}$ & 0.112 & \\
\hline & Medium & $0.879 \pm 2.921^{c}$ & $2.40 \pm 2.65^{b c}$ & $4.40 \pm 2.65$ abr & $5.74 \pm 3.51 \mathrm{aXY}$ & $<0.001$ & 0.277 \\
\hline & High & $1.15 \pm 2.18^{b}$ & $10.4 \pm 12.4^{\mathrm{a}}$ & $7.29 \pm 3.26 \mathrm{abx}$ & $8.77 \pm 4.34$ ax & 0.001 & 0.135 \\
\hline \multicolumn{2}{|c|}{$P$ oxidative group } & 0.301 & 0.149 & $<0.001$ & $<0.001$ & & \\
\hline \multirow[t]{3}{*}{ Phenylacetaldehyde } & Low & $0.740 \pm 1.723$ & $0.299 \pm 0.833$ & $0.206 \pm 0.578$ & $0.170 \pm 0.462$ & 0.375 & \\
\hline & Medium & $1.29 \pm 2.80$ & $0.309 \pm 0.665$ & $0.067 \pm 0.177$ & $0.699 \pm 1.865$ & 0.236 & \\
\hline & High & $1.50 \pm 2.39^{\mathrm{a}}$ & $0.233 \pm 0.676^{b}$ & n.d. ${ }^{b}$ & $0.065 \pm 0.268^{b}$ & 0.002 & 0.178 \\
\hline \multicolumn{2}{|c|}{$P$ oxidative group } & 0.637 & 0.949 & 0.237 & 0.229 & & \\
\hline Ethyl-hexanoate & Low & $0.012 \pm 0.019 \mathrm{bY}$ & $0.058 \pm 0.081^{b Y}$ & $0.562 \pm 0.693 \mathrm{ar}$ & $0.268 \pm 0.345 \mathrm{abY}$ & 0.001 & 0.108 \\
\hline
\end{tabular}




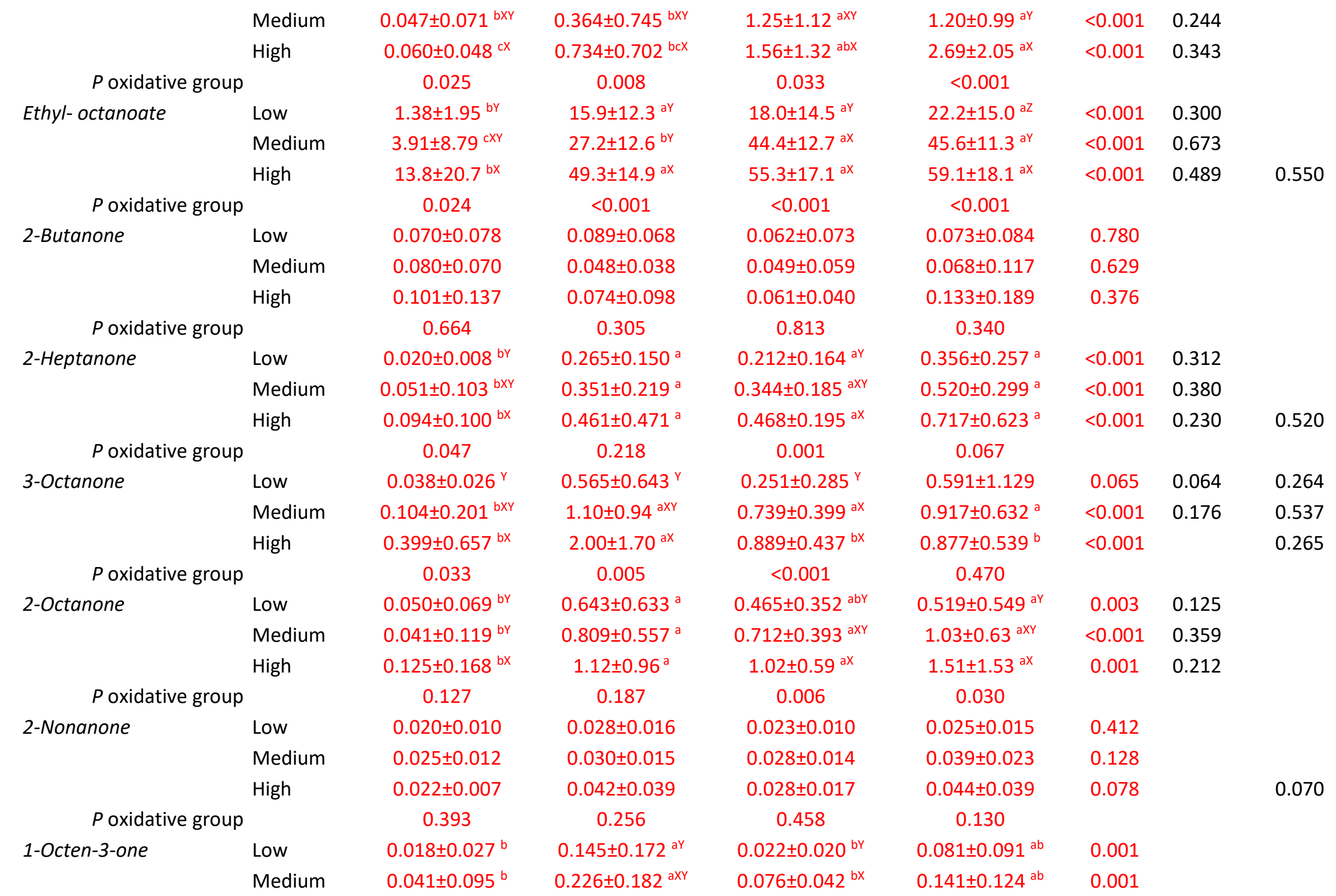




\begin{tabular}{|c|c|c|c|c|c|c|c|c|}
\hline & High & $0.110 \pm 0.223^{b}$ & $0.392 \pm 0.358^{a x}$ & $0.092 \pm 0.061 \mathrm{bx}$ & $0.112 \pm 0.093^{b}$ & \multicolumn{2}{|l|}{$<0.001$} & \\
\hline \multicolumn{2}{|c|}{$P$ oxidative group } & 0.172 & 0.026 & $<0.001$ & 0.276 & & & \\
\hline \multirow[t]{3}{*}{ 3-Octen-2-one } & Low & $0.001 \pm 0.003^{b}$ & $0.056 \pm 0.060 \mathrm{aby}$ & $0.035 \pm 0.029 \mathrm{bY}$ & $0.136 \pm 0.196^{a}$ & 0.004 & 0.136 & \\
\hline & Medium & $0.010 \pm 0.037^{b}$ & $0.059 \pm 0.037^{b Y}$ & $0.118 \pm 0.083^{b X Y}$ & $0.253 \pm 0.216^{a}$ & $<0.001$ & 0.309 & \\
\hline & High & $0.002 \pm 0.005^{b}$ & $0.156 \pm 0.146^{b x}$ & $0.187 \pm 0.169 \mathrm{abx}$ & $0.418 \pm 0.492^{\mathrm{a}}$ & $<0.001$ & 0.210 & \\
\hline \multicolumn{2}{|c|}{$P$ oxidative group } & 0.466 & 0.006 & 0.001 & 0.064 & & & \\
\hline \multirow[t]{3}{*}{ 3-Nonen-2-one } & Low & n.d. & $0.003 \pm 0.007$ & $0.001 \pm 0.002^{Y}$ & $0.005 \pm 0.007^{Y}$ & 0.031 & 0.072 & \\
\hline & Medium & n.d. ${ }^{b}$ & $0.002 \pm 0.003^{b}$ & $0.014 \pm 0.018 \mathrm{abXY}$ & $0.022 \pm 0.026^{a X Y}$ & 0.001 & 0.193 & \\
\hline & High & $0.001 \pm 0.002$ & $0.033 \pm 0.052$ & $0.018 \pm 0.025^{x}$ & $0.033 \pm 0.041 x$ & 0.031 & 0.082 & \\
\hline \multicolumn{2}{|c|}{$P$ oxidative group } & 0.156 & 0.010 & 0.031 & 0.027 & & & \\
\hline \multirow[t]{3}{*}{ 2,3-Octanedione } & Low & $0.714 \pm 1.551$ & $4.43 \pm 7.58$ & $0.936 \pm 2.048^{Y}$ & $20.9 \pm 63.4$ & 0.238 & & \\
\hline & Medium & $3.94 \pm 14.37$ & $4.41 \pm 5.29$ & $5.47 \pm 5.98^{X Y}$ & $10.1 \pm 15.9$ & 0.438 & & 0.392 \\
\hline & High & $1.10 \pm 2.50$ & $8.95 \pm 12.39$ & $10.4 \pm 16.9^{x}$ & $11.3 \pm 23.2$ & 0.222 & 0.063 & \\
\hline \multicolumn{2}{|c|}{$P$ oxidative group } & 0.496 & 0.265 & 0.049 & 0.709 & & & \\
\hline \multirow[t]{3}{*}{ 2-Pentylfuran } & Low & $0.063 \pm 0.080^{b}$ & $1.71 \pm 1.58 \mathrm{abr}$ & $1.87 \pm 2.73 \mathrm{abz}$ & $2.94 \pm 3.34$ ar & 0.008 & 0.170 & \\
\hline & Medium & $0.709 \pm 2.329^{c}$ & $4.13 \pm 3.82 \mathrm{bcXY}$ & $5.69 \pm 2.71 \mathrm{abr}$ & $8.43 \pm 5.93$ ar & $<0.001$ & 0.339 & 0.710 \\
\hline & High & $0.720 \pm 1.177^{c}$ & $9.20 \pm 11.92 \mathrm{bx}$ & $11.6 \pm 5.0^{\mathrm{abx}}$ & $18.6 \pm 12.8^{\text {ax }}$ & $<0.001$ & 0.330 & \\
\hline \multicolumn{2}{|c|}{$P$ oxidative group } & 0.362 & 0.019 & $<0.001$ & $<0.001$ & & & \\
\hline
\end{tabular}

${ }^{1}$ Oxidative groups, according TBARS values on day 9 of display from samples aged 15 days: low (<1 mg MDA/kg, $\left.n=16\right), \mathrm{medium}(1-2 \mathrm{mg} \mathrm{MDA} / \mathrm{kg}, n=15)$, and high (>2 mg $\mathrm{MDA} / \mathrm{kg}, n=17){ }^{2}$ : Root mean squared error. ${ }^{3}$ the $\mathrm{R}^{2}$ of linear and exponential regressions from each compound through time of display are shown when significant $(P \leq 0.05)$. n.d.: not detected. a-c: different superscripts within a row denote statistical differences, according the Tukey test $(P \leq 0.05)$ between display time within oxidative group for a compound. X-Z: different superscripts in the same column denote statistical differences $(P \leq 0.05)$ between oxidative groups within day on display, for a compound. 
Table 3. Mean and standard deviation for volatile compounds $(\mu \mathrm{g} / \mathrm{g}$ ) of knuckle steaks aged for 22 days under vacuum conditions and displayed in modified atmosphere packaging $\left(0,5,7\right.$ or 9 days), according oxidative group ${ }^{1}$.

\begin{tabular}{|c|c|c|c|c|c|c|c|c|}
\hline \multirow{2}{*}{ Compound } & \multirow{2}{*}{$\begin{array}{l}\text { Oxidative } \\
\text { group }\end{array}$} & \multicolumn{4}{|c|}{ Display (days) } & \multirow{2}{*}{$P$ display } & \multicolumn{2}{|c|}{ Regressions $^{3}$} \\
\hline & & 0 & 5 & 7 & 9 & & Linear & Exponential \\
\hline \multirow[t]{3}{*}{ Butanoic acid } & Low & $26.6 \pm 21.0^{a}$ & $9.59 \pm 7.58^{b Y}$ & $20.1 \pm 8.9^{a b}$ & $21.6 \pm 8.5^{\mathrm{ab}}$ & 0.011 & & \\
\hline & Medium & $19.7 \pm 10.4^{a b}$ & $14.0 \pm 9.2^{b Y}$ & $21.9 \pm 9.9^{a b}$ & $25.3 \pm 9.8^{a}$ & 0.031 & & \\
\hline & High & $30.3 \pm 13.2^{a}$ & $25.2 \pm 15.4^{\mathrm{abx}}$ & $17.8 \pm 5.6^{b}$ & $21.6 \pm 6.0^{a b}$ & 0.014 & 0.121 & 0.080 \\
\hline \multicolumn{2}{|l|}{$P$ oxidative group } & 0.165 & 0.001 & 0.385 & 0.478 & & & \\
\hline \multirow[t]{3}{*}{ Pentanoic acid } & Low & $1.26 \pm 0.70^{\mathrm{cY}}$ & $1.68 \pm 0.82^{c Y}$ & $5.27 \pm 3.28 \mathrm{bY}$ & $9.28 \pm 4.13^{a}$ & $<0.001$ & 0.400 & 0.483 \\
\hline & Medium & $1.39 \pm 0.72^{\mathrm{cY}}$ & $4.33 \pm 3.93^{b c X Y}$ & $6.34 \pm 2.20^{b X Y}$ & $12.3 \pm 4.0^{\mathrm{a}}$ & $<0.001$ & 0.532 & 0.681 \\
\hline & High & $2.27 \pm 0.89 c x$ & $6.92 \pm 3.45^{b x}$ & $8.58 \pm 4.27^{b x}$ & $12.9 \pm 4.5^{a}$ & $<0.001$ & 0.514 & 0.651 \\
\hline \multicolumn{2}{|l|}{$P$ oxidative group } & 0.001 & $<0.001$ & 0.026 & 0.239 & & & \\
\hline \multirow[t]{3}{*}{ Hexanoic acid } & Low & $10.0 \pm 5.6^{\mathrm{cY}}$ & $40.0 \pm 18.1^{c z}$ & $97.6 \pm 57.2^{b}$ & $157 \pm 63^{a}$ & $<0.001$ & 0.530 & 0.777 \\
\hline & Medium & $15.3 \pm 6.6^{\mathrm{cXY}}$ & $93.9 \pm 61.0^{b Y}$ & $124 \pm 38^{b}$ & $173 \pm 36^{a}$ & $<0.001$ & 0.670 & 0.829 \\
\hline & High & $22.8 \pm 15.2^{b x}$ & $143 \pm 59$ ax & $119 \pm 17^{a}$ & $144 \pm 25^{a}$ & $<0.001$ & 0.551 & 0.679 \\
\hline \multicolumn{2}{|l|}{$P$ oxidative group } & 0.004 & $<0.001$ & 0.163 & 0.194 & & & \\
\hline \multirow[t]{3}{*}{ Heptanoic acid } & Low & $0.504 \pm 0.254^{c}$ & $2.80 \pm 1.48^{b}$ & $4.51 \pm 1.62^{a}$ & $3.73 \pm 1.93^{a b}$ & $<0.001$ & 0.542 & \\
\hline & Medium & $0.881 \pm 0.709^{c}$ & $3.24 \pm 1.87^{b}$ & $3.50 \pm 0.98 \mathrm{ab}$ & $4.98 \pm 2.05^{a}$ & $<0.001$ & 0.491 & \\
\hline & High & $0.812 \pm 0.464^{b}$ & $3.68 \pm 1.62^{a}$ & $3.72 \pm 1.82^{a}$ & $4.44 \pm 1.88^{a}$ & $<0.001$ & 0.438 & \\
\hline \multicolumn{2}{|l|}{$P$ oxidative group } & 0.093 & 0.339 & 0.176 & 0.446 & & & \\
\hline \multirow[t]{3}{*}{ Octanoic acid } & Low & $1.79 \pm 1.10^{b}$ & $6.03 \pm 2.45^{a}$ & $7.15 \pm 2.65^{a x}$ & $3.54 \pm 0.98^{b}$ & $<0.001$ & 0.310 & 0.440 \\
\hline & Medium & $3.10 \pm 1.80^{b}$ & $6.18 \pm 3.40^{a}$ & $5.75 \pm 2.47^{\mathrm{aXY}}$ & $4.93 \pm 2.13^{a b}$ & 0.009 & 0.098 & 0.172 \\
\hline & High & $3.12 \pm 2.09^{b}$ & $6.31 \pm 3.56^{\mathrm{a}}$ & $4.49 \pm 3.19 \mathrm{abY}$ & $4.11 \pm 1.06^{a b}$ & 0.012 & & 0.092 \\
\hline \multicolumn{2}{|l|}{$P$ oxidative group } & 0.054 & 0.970 & 0.036 & 0.188 & & & \\
\hline \multirow[t]{3}{*}{ Nonanoic acid } & Low & $4.22 \pm 4.12^{b}$ & $14.3 \pm 4.7^{\mathrm{a}}$ & $16.0 \pm 7.7^{\mathrm{ax}}$ & $2.05 \pm 0.85^{b}$ & $<0.001$ & 0.125 & 0.144 \\
\hline & Medium & $7.66 \pm 6.68^{b}$ & $15.6 \pm 8.5^{\mathrm{a}}$ & $12.2 \pm 7.5^{a b X Y}$ & $5.99 \pm 6.38^{b}$ & 0.005 & & \\
\hline & High & $8.57 \pm 10.66$ & $13.0 \pm 7.8$ & $6.98 \pm 7.66^{Y}$ & $6.87 \pm 3.71$ & 0.110 & & \\
\hline$P$ oxidative group & & 0.252 & 0.620 & 0.006 & 0.126 & & & \\
\hline
\end{tabular}




\begin{tabular}{|c|c|c|c|c|c|c|c|}
\hline \multirow[t]{3}{*}{ Decanoic acid } & Low & $0.402 \pm 0.217$ & $0.397 \pm 0.104^{Y}$ & $0.522 \pm 0.148^{x}$ & $0.510 \pm 0.221$ & 0.121 & \\
\hline & Medium & $0.611 \pm 0.404$ & $0.570 \pm 0.287^{X Y}$ & $0.609 \pm 0.171^{x}$ & $0.580 \pm 0.232$ & 0.974 & \\
\hline & High & $0.568 \pm 0.226 \mathrm{ab}$ & $0.730 \pm 0.330 \mathrm{ax}$ & $0.379 \pm 0.118^{b Y}$ & $0.565 \pm 0.184^{a b}$ & 0.001 & \\
\hline \multicolumn{2}{|c|}{$P$ oxidative group } & 0.114 & 0.004 & $<0.001$ & 0.800 & & \\
\hline \multirow[t]{3}{*}{ 1-Hexanol } & Low & $9.18 \pm 19.91$ br & $43.9 \pm 103.5^{b Y}$ & $297 \pm 440$ by & $628 \pm 374^{a}$ & $<0.001$ & 0.248 \\
\hline & Medium & $15.6 \pm 22.8^{\mathrm{cr}}$ & $167 \pm 179$ bcy & $451 \pm 328$ br & $915 \pm 526^{a}$ & $<0.001$ & 0.436 \\
\hline & High & $114 \pm 129^{b x}$ & $461 \pm 277^{b x}$ & $975 \pm 447$ ax & $1082 \pm 593^{a}$ & $<0.001$ & 0.480 \\
\hline \multicolumn{2}{|c|}{$P$ oxidative group } & $<0.001$ & $<0.001$ & $<0.001$ & 0.241 & & \\
\hline \multirow[t]{3}{*}{ 1-Octen-3-ol } & Low & $0.534 \pm 0.470 \mathrm{ab}$ & $0.146 \pm 0.441^{b}$ & $0.210 \pm 0.268^{b}$ & $0.983 \pm 1.011^{a}$ & 0.004 & \\
\hline & Medium & $0.763 \pm 0.696^{a}$ & $0.095 \pm 0.164^{b}$ & $0.565 \pm 0.690^{a b}$ & $1.07 \pm 0.70^{a}$ & 0.001 & \\
\hline & High & $1.01 \pm 0.61^{\mathrm{a}}$ & $0.255 \pm 0.254^{b}$ & $0.445 \pm 0.309^{b}$ & $0.387 \pm 0.380^{b}$ & $<0.001$ & 0.234 \\
\hline \multicolumn{2}{|c|}{$P$ oxidative group } & 0.086 & 0.325 & 0.108 & 0.037 & & \\
\hline \multirow[t]{3}{*}{ Hexanal } & Low & $0.477 \pm 0.722^{b}$ & $20.6 \pm 40.3^{a b}$ & $49.3 \pm 65.1^{a}$ & $20.4 \pm 24.7^{\text {ab }}$ & 0.022 & 0.113 \\
\hline & Medium & $1.12 \pm 1.27^{b}$ & $39.8 \pm 47.9^{a}$ & $37.4 \pm 56.7$ ab & $13.3 \pm 9.0^{\mathrm{ab}}$ & 0.020 & \\
\hline & High & $14.1 \pm 31.6$ & $39.7 \pm 50.4$ & $65.8 \pm 134.3$ & $14.8 \pm 7.5$ & 0.179 & \\
\hline \multicolumn{2}{|c|}{$P$ oxidative group } & 0.075 & 0.429 & 0.696 & 0.545 & & \\
\hline \multirow[t]{3}{*}{ Heptanal } & Low & $3.34 \pm 2.71^{b}$ & $14.8 \pm 16.8^{b}$ & $19.2 \pm 22.8^{a b}$ & $37.2 \pm 32.0^{a}$ & 0.003 & 0.214 \\
\hline & Medium & $16.1 \pm 39.0$ & $14.0 \pm 11.5$ & $25.6 \pm 25.4$ & $39.7 \pm 52.4$ & 0.220 & \\
\hline & High & $10.2 \pm 7.7$ & $20.3 \pm 29.5$ & $16.6 \pm 31.3$ & $8.44 \pm 5.74$ & 0.432 & \\
\hline \multicolumn{2}{|c|}{$P$ oxidative group } & 0.289 & 0.653 & 0.636 & 0.081 & & \\
\hline \multirow[t]{3}{*}{ Nonanal } & Low & $0.215 \pm 0.282^{Y}$ & $3.52 \pm 4.71$ & $3.42 \pm 5.64$ & $1.28 \pm 0.81$ & 0.075 & \\
\hline & Medium & $0.425 \pm 0.392^{X Y}$ & $7.43 \pm 10.33$ & $11.1 \pm 18.0$ & $2.44 \pm 1.91$ & 0.040 & \\
\hline & High & $2.60 \pm 4.42^{x}$ & $4.25 \pm 8.03$ & $4.53 \pm 8.13$ & $1.21 \pm 0.96$ & 0.457 & \\
\hline \multicolumn{2}{|c|}{$P$ oxidative group } & 0.023 & 0.371 & 0.162 & 0.079 & & \\
\hline \multirow[t]{3}{*}{ (E)-2-Heptenal } & Low & $0.029 \pm 0.040$ & $0.189 \pm 0.300$ & $0.486 \pm 0.932$ & $0.422 \pm 0.346$ & 0.112 & 0.097 \\
\hline & Medium & $0.014 \pm 0.028$ & $1.37 \pm 2.56$ & $0.515 \pm 0.493$ & $0.967 \pm 0.846$ & 0.062 & \\
\hline & High & $0.040 \pm 0.042^{b}$ & $0.724 \pm 0.702^{a b}$ & $1.17 \pm 1.65^{\mathrm{a}}$ & $0.783 \pm 0.516^{a b}$ & 0.011 & 0.126 \\
\hline \multicolumn{2}{|c|}{$P$ oxidative group } & 0.159 & 0.114 & 0.179 & 0.257 & & \\
\hline (Z)-2-Octenal & Low & $0.001 \pm 0.006^{b Y}$ & $0.102 \pm 0.151 \mathrm{abY}$ & $0.202 \pm 0.219^{a}$ & $0.225 \pm 0.146^{a}$ & 0.002 & 0.253 \\
\hline
\end{tabular}




\begin{tabular}{|c|c|c|c|c|c|c|c|}
\hline & Medium & $0.036 \pm 0.069 \mathrm{bXY}$ & $0.437 \pm 0.512^{\mathrm{ax}}$ & $0.228 \pm 0.194^{a b}$ & $0.455 \pm 0.502^{a}$ & 0.010 & 0.116 \\
\hline & High & $0.061 \pm 0.085^{b x}$ & $0.449 \pm 0.239 \mathrm{ax}$ & $0.325 \pm 0.380^{a}$ & $0.265 \pm 0.235^{\mathrm{ab}}$ & 0.001 & 0.101 \\
\hline \multicolumn{2}{|c|}{$P$ oxidative group } & 0.034 & 0.008 & 0.427 & 0.314 & & \\
\hline \multirow[t]{3}{*}{ (E)-2-Nonenal } & Low & $0.044 \pm 0.045$ & $0.124 \pm 0.172$ & $0.332 \pm 0.586$ & $0.122 \pm 0.070$ & 0.114 & \\
\hline & Medium & $0.034 \pm 0.037^{b}$ & $0.558 \pm 0.730^{a}$ & $0.284 \pm 0.246^{a b}$ & $0.412 \pm 0.388^{a b}$ & 0.014 & 0.081 \\
\hline & High & $0.068 \pm 0.116^{b}$ & $0.360 \pm 0.371^{\mathrm{ab}}$ & $0.495 \pm 0.545^{a}$ & $0.334 \pm 0.268^{a b}$ & 0.011 & 0.117 \\
\hline \multicolumn{2}{|c|}{$P$ oxidative group } & 0.428 & 0.055 & 0.440 & 0.173 & & \\
\hline \multirow[t]{3}{*}{$(E, E)-2,4-$ Nonadienal } & Low & n.d. & $0.291 \pm 0.440$ & $1.08 \pm 2.15$ & $0.534 \pm 0.440$ & 0.093 & 0.077 \\
\hline & Medium & n.d. & $3.55 \pm 7.65$ & $0.919 \pm 1.500$ & $1.35 \pm 1.31$ & 0.115 & \\
\hline & High & $0.130 \pm 0.304$ & $1.52 \pm 1.73$ & $4.31 \pm 9.69$ & $1.45 \pm 0.87$ & 0.121 & \\
\hline \multicolumn{2}{|c|}{$P$ oxidative group } & 0.068 & 0.140 & 0.205 & 0.186 & & \\
\hline \multirow[t]{3}{*}{ (E)-2-Undecenal } & Low & $0.114 \pm 0.127^{\mathrm{br}}$ & $1.18 \pm 0.80$ aby & $1.89 \pm 1.544^{\mathrm{aY}}$ & $2.21 \pm 0.54^{\mathrm{a}}$ & $<0.001$ & 0.418 \\
\hline & Medium & $0.258 \pm 0.236^{b X Y}$ & $2.83 \pm 2.43^{\mathrm{ax}}$ & $2.54 \pm 1.10^{\mathrm{aXY}}$ & $3.33 \pm 1.30^{a}$ & $<0.001$ & 0.354 \\
\hline & High & $0.444 \pm 0.487^{\mathrm{bx}}$ & $4.06 \pm 1.57^{\mathrm{ax}}$ & $3.36 \pm 1.15^{\mathrm{ax}}$ & $3.64 \pm 1.39^{a}$ & $<0.001$ & 0.441 \\
\hline \multicolumn{2}{|c|}{$P$ oxidative group } & 0.021 & $<0.001$ & 0.008 & 0.080 & & \\
\hline \multirow[t]{3}{*}{ (E,Z)-2,4-Decadienal } & Low & $0.016 \pm 0.045^{Y}$ & $0.989 \pm 1.47$ & $1.07 \pm 1.30$ & $0.232 \pm 0.150$ & 0.023 & 0.077 \\
\hline & Medium & $0.023 \pm 0.038^{\mathrm{bXY}}$ & $3.03 \pm 3.17^{\mathrm{a}}$ & $0.843 \pm 0.930^{b}$ & $0.560 \pm 0.475^{b}$ & $<0.001$ & \\
\hline & High & $0.163 \pm 0.277^{x}$ & $2.23 \pm 3.12$ & $1.83 \pm 3.15$ & $0.524 \pm 0.260$ & 0.033 & \\
\hline \multicolumn{2}{|c|}{$P$ oxidative group } & 0.026 & 0.130 & 0.385 & 0.163 & & \\
\hline \multirow[t]{3}{*}{$(E, E)-2,4$-Decadienal } & Low & n.d. ${ }^{b}$ & $3.28 \pm 4.97 \mathrm{abr}$ & $7.26 \pm 8.94^{a}$ & $4.21 \pm 1.95 \mathrm{ab}$ & 0.008 & 0.164 \\
\hline & Medium & $0.068 \pm 0.186^{b}$ & $13.3 \pm 15.2 \mathrm{ax}$ & $6.49 \pm 5.14$ ab & $7.04 \pm 3.67$ ab & 0.001 & 0.081 \\
\hline & High & $0.428 \pm 0.822^{b}$ & $12.1 \pm 11.0^{\mathrm{aXY}}$ & $10.9 \pm 11.6^{a}$ & $6.63 \pm 2.20 \mathrm{ab}$ & 0.001 & 0.116 \\
\hline \multicolumn{2}{|c|}{$P$ oxidative group } & 0.039 & 0.035 & 0.341 & 0.138 & & \\
\hline \multirow[t]{3}{*}{ Phenylacetaldehyde } & Low & $2.16 \pm 4.86$ & $0.647 \pm 0.966$ & $0.814 \pm 2.006$ & $3.27 \pm 8.01$ & 0.430 & \\
\hline & Medium & $8.74 \pm 18.47$ & $0.560 \pm 0.828$ & $0.976 \pm 2.113$ & $1.36 \pm 4.73$ & 0.083 & 0.090 \\
\hline & High & $17.8 \pm 55.0$ & $1.04 \pm 3.45$ & $0.287 \pm 1.182$ & n.d. & 0.212 & 0.062 \\
\hline \multicolumn{2}{|c|}{$P$ oxidative group } & 0.431 & 0.806 & 0.524 & 0.345 & & \\
\hline \multirow[t]{2}{*}{ Ethyl- hexanoate } & Low & $0.084 \pm 0.114^{\mathrm{bY}}$ & $0.246 \pm 0.854^{b}$ & $0.285 \pm 0.473^{b}$ & $1.39 \pm 0.71^{\mathrm{a}}$ & $<0.001$ & 0.150 \\
\hline & Medium & $0.147 \pm 0.149^{b X Y}$ & $0.145 \pm 0.185^{b}$ & $0.944 \pm 1.283^{b}$ & $2.93 \pm 2.13^{\mathrm{a}}$ & $<0.001$ & 0.274 \\
\hline
\end{tabular}




\begin{tabular}{|c|c|c|c|c|c|c|c|c|}
\hline \multirow{2}{*}{\multicolumn{2}{|c|}{ P oxidative group }} & $0.307 \pm 0.262^{b x}$ & $0.439 \pm 0.404^{a b}$ & $0.875 \pm 0.706^{a b}$ & $1.15 \pm 1.39^{a}$ & 0.012 & 0.135 & \\
\hline & & 0.004 & 0.313 & 0.088 & 0.030 & & & \\
\hline \multirow[t]{3}{*}{ Ethyl-octanoate } & Low & $0.945 \pm 0.995 \mathrm{br}$ & $26.9 \pm 24.7^{a}$ & $33.3 \pm 27.1^{\mathrm{a}}$ & $48.0 \pm 11.3^{a}$ & $<0.001$ & 0.403 & 0.736 \\
\hline & Medium & $4.26 \pm 5.55^{\mathrm{bXY}}$ & $37.4 \pm 19.6^{a}$ & $43.5 \pm 19.1^{a}$ & $50.6 \pm 15.2^{a}$ & $<0.001$ & 0.557 & 0.682 \\
\hline & High & $9.11 \pm 10.70^{b x}$ & $37.4 \pm 10.0^{a}$ & $38.6 \pm 12.9^{a}$ & $38.2 \pm 14.0^{a}$ & $<0.001$ & 0.469 & 0.579 \\
\hline \multicolumn{2}{|c|}{$P$ oxidative group } & 0.007 & 0.214 & 0.394 & 0.091 & & & \\
\hline \multirow[t]{3}{*}{ 2-Butanone } & Low & $0.051 \pm 0.051$ & $0.061 \pm 0.057$ & $0.065 \pm 0.068$ & $0.096 \pm 0.048^{x}$ & 0.462 & & \\
\hline & Medium & $0.313 \pm 0.706$ & $0.061 \pm 0.061$ & $0.079 \pm 0.038$ & $0.071 \pm 0.048^{X Y}$ & 0.193 & & \\
\hline & High & $0.203 \pm 0.333$ & $0.074 \pm 0.078$ & $0.051 \pm 0.031$ & $0.046 \pm 0.024^{Y}$ & 0.045 & 0.115 & \\
\hline \multicolumn{2}{|c|}{$P$ oxidative group } & 0.263 & 0.824 & 0.261 & 0.047 & & & \\
\hline \multirow[t]{3}{*}{ 2-Heptanone } & Low & $0.026 \pm 0.026^{c}$ & $0.212 \pm 0.141 \mathrm{bc}$ & $0.314 \pm 0.259^{b}$ & $0.742 \pm 0.225^{a}$ & $<0.001$ & 0.480 & \\
\hline & Medium & $0.067 \pm 0.077^{b}$ & $0.411 \pm 0.431^{a}$ & $0.469 \pm 0.270^{a}$ & $0.613 \pm 0.379^{a}$ & $<0.001$ & 0.295 & 0.520 \\
\hline & High & $0.067 \pm 0.056^{b}$ & $0.511 \pm 0.374^{a}$ & $0.477 \pm 0.180^{a}$ & $0.634 \pm 0.149^{a}$ & $<0.001$ & 0.443 & 0.635 \\
\hline \multicolumn{2}{|c|}{$P$ oxidative group } & 0.067 & 0.053 & 0.113 & 0.630 & & & \\
\hline \multirow[t]{3}{*}{ 3-Octanone } & Low & $0.028 \pm 0.027^{Y}$ & $0.406 \pm 0.367^{Y}$ & $1.13 \pm 2.44$ & $1.32 \pm 1.09$ & 0.089 & 0.110 & 0.612 \\
\hline & Medium & $0.121 \pm 0.167^{b X Y}$ & $1.56 \pm 1.71^{\text {ax }}$ & $0.838 \pm 0.668 \mathrm{ab}$ & $0.874 \pm 0.482^{a b}$ & 0.002 & 0.075 & 0.431 \\
\hline & High & $0.169 \pm 0.218^{c x}$ & $0.966 \pm 0.486 \mathrm{aXY}$ & $0.772 \pm 0.599 a b$ & $0.473 \pm 0.272 b c$ & $<0.001$ & 0.106 & 0.325 \\
\hline \multicolumn{2}{|c|}{$P$ oxidative group } & 0.048 & 0.014 & 0.774 & 0.019 & & & \\
\hline \multirow[t]{3}{*}{ 2-Octanone } & Low & $0.031 \pm 0.049^{b}$ & $0.457 \pm 0.259^{a b}$ & $0.828 \pm 0.970^{a}$ & $1.04 \pm 0.71^{\mathrm{a}}$ & 0.001 & 0.284 & \\
\hline & Medium & $0.096 \pm 0.129^{b}$ & $1.13 \pm 1.18^{a}$ & $1.01 \pm 0.57^{a}$ & $1.18 \pm 0.80^{a}$ & 0.001 & 0.224 & \\
\hline & High & $0.099 \pm 0.125^{b}$ & $0.809 \pm 0.566^{a}$ & $0.736 \pm 0.416^{a}$ & $0.655 \pm 0.527^{a}$ & $<0.001$ & 0.213 & \\
\hline \multicolumn{2}{|c|}{$P$ oxidative group } & 0.138 & 0.064 & 0.520 & 0.159 & & & \\
\hline \multirow[t]{3}{*}{ 2-Nonanone } & Low & $0.010 \pm 0.007^{b}$ & $0.016 \pm 0.007^{b}$ & $0.021 \pm 0.015^{b}$ & $0.068 \pm 0.077^{a}$ & $<0.001$ & 0.151 & \\
\hline & Medium & $0.015 \pm 0.007$ & $0.038 \pm 0.051$ & $0.031 \pm 0.017$ & $0.045 \pm 0.026$ & 0.065 & 0.101 & \\
\hline & High & $0.013 \pm 0.006^{b}$ & $0.028 \pm 0.022^{a}$ & $0.027 \pm 0.017 \mathrm{ab}$ & $0.031 \pm 0.012^{a}$ & 0.007 & 0.164 & \\
\hline \multicolumn{2}{|c|}{$P$ oxidative group } & 0138 & 0.167 & 0.232 & 0.146 & & & \\
\hline \multirow[t]{3}{*}{ 1-Octen-3-one } & Low & $0.005 \pm 0.009 \mathrm{bY}$ & $0.102 \pm 0.123 \mathrm{abY}$ & $0.138 \pm 0.136^{a}$ & $0.068 \pm 0.042^{a b}$ & 0.004 & 0.163 & \\
\hline & Medium & $0.017 \pm 0.025^{\mathrm{bXY}}$ & $0.311 \pm 0.310$ ax & $0.134 \pm 0.123^{b}$ & $0.098 \pm 0.055^{b}$ & $<0.001$ & & \\
\hline & High & $0.092 \pm 0.157^{x}$ & $0.147 \pm 0.141 \mathrm{XY}$ & $0.196 \pm 0.255$ & $0.074 \pm 0.045$ & 0.194 & & 0.093 \\
\hline
\end{tabular}


$P$ oxidative group

3-Octen-2-one

Low

Medium

0.023

0.020

0.569

0.359

High

$0.001 \pm 0.001 \mathrm{XY}$

$0.002 \pm 0.004^{x}$

$P$ oxidative group

3-Nonen-2-one

Low

Medium

High

$P$ oxidative group

2,3-Octanedione

Low

Medium

High

$P$ oxidative group

2-Pentylfuran

Low

Medium

High

\subsection{8}

n.d.

n.d. ${ }^{b}$

0.340

$0.058 \pm 0.038$

$0.124 \pm 0.124^{b}$

$2.78 \pm 7.17$

0.126

$0.065 \pm 0.077^{\text {by }}$

$0.345 \pm 0.440 \mathrm{bXY}$

$0.567 \pm 0.766^{c x}$

0.029
$0.060 \pm 0.048$

$0.445 \pm 1.090$

$0.177 \pm 0.120$

0.228

$0.005 \pm 0.009$

$0.039 \pm 0.059$

0.050

$23.4 \pm 43.1$

$26.2 \pm 31.7^{\text {a }}$

$9.83 \pm 14.03$

0.291

$1.54 \pm 1.98^{b}$

$8.82 \pm 16.89$ ab

$9.56 \pm 5.55^{b}$

0.069
$0.033 \pm 0.034$ a

\begin{abstract}
$0.291 \pm 0.561$
$0.221 \pm 0.213$

$0.387 \pm 0.755$

0.710

$0.071 \pm 0.208$

$0.029 \pm 0.034$

$0.025 \pm 0.036$ ab

0.504

$9.10 \pm 10.00$

$4.75 \pm 6.22^{b}$

$9.23 \pm 17.46$

0.530

$6.25 \pm 10.75$ abr

$7.36 \pm 5.75$ abr

$17.1 \pm 12.2 \mathrm{abx}$
\end{abstract}

0.006
$0.095 \pm 0.081$

$0.267 \pm 0.342$

$0.174 \pm 0.125$

0.320

$0.006 \pm 0.007$

$0.026 \pm 0.042$

$0.016 \pm 0.017 \mathrm{ab}$

0.357

$3.94 \pm 7.08$

$1.80+1.07^{b}$

$2.44 \pm 2.19$

0.458

$8.91 \pm 6.72^{\text {a }}$

$17.0 \pm 11.7^{a}$

$20.2 \pm 12.9^{\text {a }}$

0.161
0.064

0.245

0.057

0.281

0.063

0.071

0.073

0.062

$<0.001$

0.174

0.007

0.002

0.176

0.198

$<0.001$

0.415
0.465

0.294

0.142

0.672

0.729

${ }^{1}$ Oxidative groups, according TBARS values on day 9 of display from samples aged 15 days: low (<1 mg MDA/kg, $\left.n=16\right)$, medium (1-2 mg MDA/kg, $\left.n=15\right)$, and high (>2 mg $\mathrm{MDA} / \mathrm{kg}, n=17){ }^{2}$ : Root mean squared error. ${ }^{3}$ : the $\mathrm{R}^{2}$ of linear and exponential regressions from each compound through time of display are shown when significant $(P \leq 0.05)$. n.d.: not detected. a-c: different superscripts within a row denote statistical differences, according the Tukey test $(P \leq 0.05)$ between display time within oxidative group for a compound. X-Z: different superscripts in the same column denote statistical differences $(P \leq 0.05)$ between oxidative groups within day on display, for a compound. 
Table 4. Mean and standard deviation for intensity ${ }^{1}$ of odours and TBARS (mg MDA/kg muscle) of raw knuckle steaks aged for 15 days under vacuum conditions and displayed in modified atmosphere packaging $\left(0,5,7\right.$ or 9 days) according oxidative group ${ }^{2}$.

\begin{tabular}{|c|c|c|c|c|c|c|c|c|}
\hline \multirow{2}{*}{ Attribute } & \multirow{2}{*}{$\begin{array}{l}\text { Oxidative } \\
\text { group }\end{array}$} & \multicolumn{4}{|c|}{ Display (days) } & \multirow{2}{*}{$P$ display } & \multicolumn{2}{|c|}{ Regressions $^{3}$} \\
\hline & & 0 & 5 & 7 & 9 & & Linear & Exponential \\
\hline \multirow[t]{3}{*}{ Raw meat odour } & Low & $4.15 \pm 2.26 \mathrm{aXY}$ & $3.35 \pm 1.26 \mathrm{abx}$ & $2.39 \pm 0.64^{b c x}$ & $1.98 \pm 0.60^{c x}$ & $<0.001$ & 0.375 & 0.252 \\
\hline & Medium & $4.66 \pm 2.25$ ax & $3.23 \pm 1.21 \mathrm{bx}$ & $2.35 \pm 0.70^{\mathrm{bx}}$ & $2.04 \pm 0.49^{b x}$ & $<0.001$ & 0.375 & 0.323 \\
\hline & High & $2.82 \pm 1.12^{\mathrm{ar}}$ & $2.26 \pm 0.86^{a b Y}$ & $1.70 \pm 0.45^{\mathrm{bcY}}$ & $1.29 \pm 0.57^{c \gamma}$ & $<0.001$ & 0.342 & 0.437 \\
\hline \multicolumn{2}{|l|}{$P$ oxidative group } & 0.026 & 0.014 & 0.003 & $<0.001$ & & & \\
\hline \multirow[t]{3}{*}{ Rancid odour } & Low & $1.92 \pm 0.94 \mathrm{bXY}$ & $3.20 \pm 0.66^{\mathrm{ar}}$ & $3.43 \pm 0.69$ ar & $3.61 \pm 0.73^{\text {az }}$ & $<0.001$ & 0.429 & 0.396 \\
\hline & Medium & $1.46 \pm 0.65^{c \gamma}$ & $3.55 \pm 0.77^{b X Y}$ & $3.89 \pm 1.11^{b r}$ & $5.09 \pm 1.17^{\mathrm{ar}}$ & $<0.001$ & 0.659 & 0.691 \\
\hline & High & $2.35 \pm 0.73 \mathrm{dx}$ & $4.21 \pm 0.89 c x$ & $5.30 \pm 0.73^{b x}$ & $6.25 \pm 0.98$ ax & $<0.001$ & 0.755 & 0.710 \\
\hline \multicolumn{2}{|l|}{$P$ oxidative group } & 0.009 & 0.002 & $<0.001$ & $<0.001$ & & & \\
\hline \multirow[t]{3}{*}{ Metallic odour } & Low & $0.271 \pm 0.374$ & $0.254 \pm 0.213$ & $0.422 \pm 0.437$ & $0.354 \pm 0.374$ & 0.526 & & \\
\hline & Medium & $0.455 \pm 0.464$ & $0.151 \pm 0.146$ & $0.202 \pm 0.383$ & $0.188 \pm 0.207$ & 0.053 & 0.092 & \\
\hline & High & $0.527 \pm 0.292^{\mathrm{a}}$ & $0.329 \pm 0.273^{a b}$ & $0.147 \pm 0.153^{b}$ & $0.371 \pm 0.126^{a}$ & $<0.001$ & 0.124 & \\
\hline \multicolumn{2}{|l|}{$P$ oxidative group } & 0.150 & 0.085 & 0.064 & 0.101 & & & \\
\hline \multirow[t]{2}{*}{ Sweet odour } & Low & $2.20 \pm 1.66$ & $1.31 \pm 1.00$ & $2.01 \pm 0.60^{x}$ & $1.77 \pm 0.55$ & 0.107 & & \\
\hline & Medium & $2.56 \pm 1.03^{a}$ & $1.29 \pm 0.66^{b}$ & $1.41 \pm 0.34^{b y}$ & $1.39 \pm 0.77^{b}$ & $<0.001$ & 0.263 & 0.160 \\
\hline
\end{tabular}




\begin{tabular}{|c|c|c|c|c|c|c|c|c|}
\hline & High & $1.98 \pm 0.80^{a}$ & $1.59 \pm 0.68^{a b}$ & $1.38 \pm 0.51^{b y}$ & $1.27 \pm 0.49^{b}$ & 0.009 & 0.162 & \\
\hline \multicolumn{2}{|l|}{$P$ oxidative group } & 0.408 & 0.495 & 0.001 & 0.063 & & & \\
\hline \multirow[t]{3}{*}{ Musty odour } & Low & $0.546 \pm 0.434^{X Y}$ & $0.551 \pm 0.420$ & $0.554 \pm 0.384^{Y}$ & $0.500 \pm 0.322^{Y}$ & 0.977 & & \\
\hline & Medium & $0.338 \pm 0.356^{Y}$ & $0.690 \pm 0.623$ & $0.837 \pm 0.719^{X Y}$ & $0.777 \pm 0.466^{Y}$ & 0.078 & 0.101 & \\
\hline & High & $0.780 \pm 0.489^{b x}$ & $0.994 \pm 0.627^{b}$ & $1.21 \pm 0.82^{b x}$ & $1.95 \pm 1.07^{\mathrm{ax}}$ & $<0.001$ & 0.187 & \\
\hline \multicolumn{2}{|l|}{$P$ oxidative group } & 0.022 & 0.081 & 0.027 & $<0.001$ & & & \\
\hline \multirow[t]{3}{*}{ Cooked meat odour } & Low & $0.455 \pm 0.602$ & $0.689 \pm 0.288$ & $0.467 \pm 0.438^{X Y}$ & $0.791 \pm 0.383^{X Y}$ & 0.091 & & \\
\hline & Medium & $0.177 \pm 0.337^{b}$ & $0.953 \pm 0.662^{a}$ & $0.389 \pm 0.472$ by & $1.13 \pm 0.65^{a x}$ & $<0.001$ & 0.183 & \\
\hline & High & $0.196 \pm 0.344^{b}$ & $0.664 \pm 0.451^{a}$ & $0.823 \pm 0.365^{a x}$ & $0.735 \pm 0.295^{\mathrm{aY}}$ & $<0.001$ & 0.270 & \\
\hline \multicolumn{2}{|l|}{$P$ oxidative group } & 0.156 & 0.196 & 0.012 & 0.040 & & & \\
\hline \multirow[t]{3}{*}{ Sulphury odour } & Low & $1.31 \pm 1.32$ & $0.729 \pm 0.520^{Y}$ & $1.07 \pm 0.60$ & $0.948 \pm 0.363$ & 0.224 & & \\
\hline & Medium & $1.89 \pm 1.91$ & $0.836 \pm 0.744^{Y}$ & $1.20 \pm 0.80$ & $1.31 \pm 0.52$ & 0.092 & & \\
\hline & High & $2.34 \pm 1.50^{a}$ & $1.44 \pm 0.69 \mathrm{bx}$ & $1.49 \pm 0.69 \mathrm{~b}$ & $1.32 \pm 0.58^{b}$ & 0.009 & 0.145 & \\
\hline \multicolumn{2}{|l|}{$P$ oxidative group } & 0.183 & 0.007 & 0.231 & 0.063 & & & \\
\hline \multirow[t]{4}{*}{ TBARS value } & Low & $0.067 \pm 0.012^{b}$ & $0.356 \pm 0.177^{a b Y}$ & $0.661 \pm 0.650 \mathrm{aY}$ & $0.629 \pm 0.260 \mathrm{az}$ & $<0.001$ & 0.294 & 0.735 \\
\hline & Medium & $0.070 \pm 0.015^{d}$ & $0.626 \pm 0.148^{c \gamma}$ & $1.00 \pm 0.33^{b Y}$ & $1.43 \pm 0.22 \mathrm{aY}$ & $<0.001$ & 0.832 & 0.931 \\
\hline & High & $0.074 \pm 0.013^{d}$ & $1.36 \pm 0.54^{c x}$ & $1.99 \pm 0.87^{b x}$ & $3.07 \pm 0.63^{a x}$ & $<0.001$ & 0.751 & 0.893 \\
\hline & & 0.260 & $<0.001$ & $<0.001$ & $<0.001$ & & & \\
\hline
\end{tabular}


${ }^{1} 0$ (no detected) - 10 (very intense). ${ }^{2}$ Oxidative groups, according TBARS values on day 9 of display from samples aged 15 days: low (<1 mg MDA/kg), medium (1-2 mg $\mathrm{MDA} / \mathrm{kg}$ ), and high ( $>2 \mathrm{mg} \mathrm{MDA} / \mathrm{kg}$ ). ${ }^{3:}$ the $\mathrm{R}^{2}$ of linear and exponential regressions from each compound through time of display are shown when significant ( $\left.P \leq 0.05\right)$.

RMSE: Root mean squared error. a-d: different superscripts within a row denote statistical differences, according the Tukey test ( $\mathrm{P} \leq 0.05)$, between display time within oxidative group for a compound. X-Z: different superscripts in the same column denote statistical differences $(P \leq 0.05)$ between oxidative groups within day on display, for a compound. 
Table 5. Mean and standard deviation for intensity ${ }^{1}$ of odours and TBARS (mg MDA/kg muscle) of raw knuckle steaks aged for 22 days under vacuum conditions and displayed in modified atmosphere packaging $\left(0,5,7\right.$ or 9 days) according oxidative group ${ }^{2}$.

\begin{tabular}{|c|c|c|c|c|c|c|c|c|}
\hline \multirow{2}{*}{ Attribute } & \multirow{2}{*}{$\begin{array}{l}\text { Oxidative } \\
\text { group }\end{array}$} & \multicolumn{4}{|c|}{ Display (days) } & \multirow{2}{*}{$P$ display } & \multicolumn{2}{|c|}{ Regressions $^{3}$} \\
\hline & & 0 & 5 & 7 & 9 & & Linear & Exponential \\
\hline \multirow[t]{3}{*}{ Raw meat odour } & Low & $2.75 \pm 0.67^{a}$ & $1.72 \pm 0.41^{b c}$ & $2.14 \pm 0.46^{b x}$ & $1.44 \pm 0.39^{c x}$ & $<0.001$ & 0.324 & 0.288 \\
\hline & Medium & $2.33 \pm 0.82^{a}$ & $1.84 \pm 0.39 \mathrm{ab}$ & $1.64 \pm 0.72^{b x}$ & $1.26 \pm 0.68^{b x}$ & 0.002 & 0.244 & 0.231 \\
\hline & High & $2.72 \pm 0.63^{a}$ & $1.70 \pm 0.40^{b}$ & $0.989 \pm 0.583^{\mathrm{cY}}$ & $0.498 \pm 0.312^{d Y}$ & $<0.001$ & 0.727 & 0.675 \\
\hline \multicolumn{2}{|l|}{$P$ oxidative group } & 0.194 & 0.583 & $<0.001$ & $<0.001$ & & & \\
\hline \multirow[t]{3}{*}{ Rancid odour } & Low & $2.24 \pm 0.76^{c}$ & $3.29 \pm 1.13^{b y}$ & $4.08 \pm 0.67^{\mathrm{br}}$ & $5.20 \pm 0.91 \mathrm{ar}$ & $<0.001$ & 0.532 & 0.499 \\
\hline & Medium & $2.45 \pm 0.53^{c}$ & $4.51 \pm 0.72^{b x}$ & $4.88 \pm 1.40^{\mathrm{bXY}}$ & $6.06 \pm 1.53 \mathrm{aXY}$ & $<0.001$ & 0.583 & 0.636 \\
\hline & High & $2.58 \pm 0.87^{c}$ & $5.25 \pm 1.14$ bx & $5.82 \pm 1.26^{b x}$ & $7.13 \pm 1.64 \mathrm{ax}$ & $<0.001$ & 0.648 & 0.672 \\
\hline \multicolumn{2}{|l|}{$P$ oxidative group } & 0.417 & $<0.001$ & $<0.001$ & 0.034 & & & \\
\hline \multirow[t]{3}{*}{ Metallic odour } & Low & $0.638 \pm 0.391^{a}$ & $0.270 \pm 0.240^{b}$ & $0.133 \pm 0.155^{b}$ & $0.277 \pm 0.171^{b}$ & $<0.001$ & 0.317 & \\
\hline & Medium & $0.394 \pm 0.314^{a}$ & $0.325 \pm 0.147^{a b}$ & $0.178 \pm 0.146^{b}$ & $0.331 \pm 0.123^{a b}$ & 0.034 & & \\
\hline & High & $0.770 \pm 0.575^{a}$ & $0.317 \pm 0.116^{b}$ & $0.225 \pm 0.165^{b}$ & $0.436 \pm 0.199^{b}$ & $<0.001$ & 0.194 & \\
\hline \multicolumn{2}{|l|}{$P$ oxidative group } & 0.067 & 0.645 & 0.255 & 0.124 & & & \\
\hline \multirow[t]{3}{*}{ Sweet odour } & Low & $1.63 \pm 0.38$ & $1.53 \pm 0.81$ & $1.37 \pm 0.59$ & $1.20 \pm 0.49$ & 0.406 & & \\
\hline & Medium & $1.45 \pm 0.67$ & $1.39 \pm 0.73$ & $1.30 \pm 0.80$ & $0.791 \pm 0.370$ & 0.065 & 0.074 & \\
\hline & High & $1.62 \pm 0.60^{a}$ & $0.957 \pm 0.569^{b}$ & $1.42 \pm 0.48 \mathrm{ab}$ & $0.999 \pm 0.565^{b}$ & 0.002 & 0.094 & \\
\hline
\end{tabular}


$P$ oxidative group

Musty odour

\section{Low}

Medium

High

$P$ oxidative group

Cooked meat odour

Low

Medium

High

$P$ oxidative group

Sulphury odour

Low

Medium

High

$P$ oxidative group

TBARS value

Low

High
0.607

$0.327 \pm 0.148^{b Y}$

$0.763 \pm 0.550^{b x}$

$0.568 \pm 0.405^{b X Y}$

0.015

$0.321 \pm 0.390^{b}$

$0.185 \pm 0.245^{c}$

$0.318 \pm 0.383^{c}$

0.467

$2.24 \pm 0.85^{\mathrm{aXY}}$

$2.55 \pm 1.26^{a x}$

$$
1.50 \pm 0.64 \text { bY }
$$

0.008

$0.071 \pm 0.011^{c Y}$

$0.080 \pm 0.014^{c Y}$

$0.104 \pm 0.021^{c x}$
0.062

$0.575 \pm 0.372^{b}$

$0.807 \pm 0.344^{b}$

$0.852 \pm 0.407^{b}$

0.101

$0.400 \pm 0.519^{b Y}$

$0.698 \pm 0.510^{b X Y}$

$0.897 \pm 0.506 b x$

0.030

$0.833 \pm 0.576 \mathrm{cr}$

$1.43 \pm 0.61^{b x}$

$1.32 \pm 0.51^{\mathrm{bXY}}$

0.014

$0.506 \pm 0.391^{\mathrm{bcY}}$

$0.832 \pm 0.394^{\text {bY }}$

$1.39 \pm 0.55 \mathrm{bx}$
0.863

$0.632 \pm 0.507^{b}$

$2.03 \pm 0.59^{a}$

$<0.001$

0.312

$0.587 \pm 0.495^{b}$

$1.62 \pm 0.86^{a}$

$<0.001$

0.079

$0.450 \pm 0.376^{b}$

$1.81 \pm 0.71^{a}$

$<0.001$

0.174

0.505

0.561

$0.555 \pm 0.465^{b}$

$1.50 \pm 0.33^{a}$

$<0.001$

0.192

$0.433 \pm 0.371 b c$

$1.14 \pm 0.43^{a}$

$<0.001$

0.288

$0.774 \pm 0.357^{b}$

$1.47 \pm 0.58^{a}$

$<0.001$

0.359

0.059

$0.999 \pm 0.572 \mathrm{bcY}$

0.174

$1.39 \pm 0.62^{b X Y}$

$1.70 \pm 0.97^{a b}$

$<0.001$

0.218

$1.56 \pm 0.69^{b x}$

$2.00 \pm 0.67^{a b}$

0.001

0.107

$2.13 \pm 0.52^{a}$

0.004

0.065

0.049

0.049

0.439

\section{$0.796 \pm 0.545^{b Y}$}

\section{$1.60 \pm 0.56^{\mathrm{aY}}$}

$<0.001$

0.498

0.792

$1.20 \pm 0.48$ bY

$2.19 \pm 0.85^{\mathrm{aXY}}$

$<0.001$

0.632

0.872

$2.47 \pm 1.05^{a x}$

$3.08 \pm 1.02 \mathrm{ax}$

$<0.001$

0.678

0.899

\section{$P$ oxidative group}

$<0.001$

$<0.001$

$<0.001$

0.005

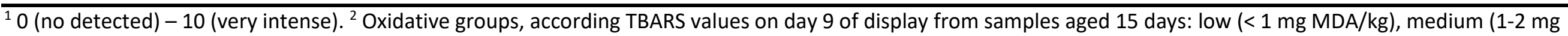

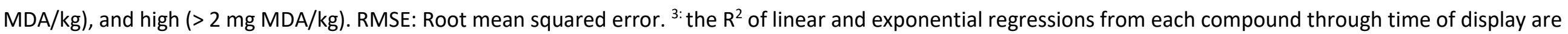


shown when significant ( $P \leq 0.05)$. a-d: different superscripts within a row denote statistical differences, according the Tukey test $(P \leq 0.05)$, between display time within oxidative group for a compound. $\mathrm{X}, \mathrm{Y}$ : different superscripts in the same column denote statistical differences $(P \leq 0.05)$ between oxidative groups within day on display, for a compound. 
2 Table 6. Pearson correlations coefficients between the volatile compounds, TBARS and odour attributes of knuckle steaks aged for 15 or 22 days under 3 vacuum conditions and displayed in modified atmosphere packaging $(0,5,7$ or 9 days).

\begin{tabular}{|c|c|c|c|c|c|c|c|c|}
\hline & TBARS & Raw meat & Rancid & Mettalic & Sweet & Moisty & $\begin{array}{c}\text { Cooked } \\
\text { meat }\end{array}$ & Sulphury \\
\hline Butanoic acid & ns & $-0.257^{* * *}$ & ns & $0.208^{* * *}$ & $-0.280^{* * *}$ & ns & ns & ns \\
\hline Pentanoic acid & $0.814^{* * *}$ & $-0.503^{* * *}$ & $0.755^{* * *}$ & ns & $-0.364^{* * *}$ & $0.447^{* * *}$ & $0.429^{* * *}$ & ns \\
\hline Hexanoic acid & $0.698^{* * *}$ & $-0.446^{* * *}$ & $0.688^{* * *}$ & $-0.170^{* * *}$ & $-0.366^{* * *}$ & $0.389^{* * *}$ & $0.422^{* * *}$ & ns \\
\hline Heptanoic acid & $0.637^{* * *}$ & $-0.350^{* * *}$ & $0.629^{* * *}$ & $-0.230^{* * *}$ & $-0.242^{* * *}$ & $0.347^{* * *}$ & $0.353^{* * *}$ & ns \\
\hline Octanoic acid & $0.106^{*}$ & ns & $0.184^{* * *}$ & $-0.287^{* * *}$ & ns & ns & $0.108^{*}$ & $-0.191^{* * *}$ \\
\hline Nonanoic acid & ns & $0.171^{* * *}$ & ns & $-0.228^{* * *}$ & ns & ns & ns & $-0.222^{* * *}$ \\
\hline Decanoic acid & ns & $0.108^{*}$ & ns & $-0.135^{* *}$ & ns & ns & ns & ns \\
\hline 1-Hexanol & $0.822^{* * *}$ & $-0.459^{* * *}$ & $0.706^{* * *}$ & ns & $-0.289^{* * *}$ & $0.403^{* * *}$ & $0.368^{* * *}$ & ns \\
\hline 1-Octen-3-ol & $0.134^{* *}$ & $-0.221^{* * *}$ & ns & $0.105^{*}$ & $-0.112^{*}$ & $0.147^{* *}$ & ns & ns \\
\hline Hexanal & $0.135^{* *}$ & ns & $0.177^{* * *}$ & $-0.136^{* *}$ & ns & ns & $0.176^{* * *}$ & ns \\
\hline Heptanal & $0.175^{* * *}$ & ns & $0.158^{* *}$ & $-0.119^{*}$ & $-0.107^{*}$ & $0.150^{* *}$ & ns & ns \\
\hline Nonanal & ns & ns & ns & $-0.106 *$ & ns & ns & ns & ns \\
\hline (E)-2-Heptenal & $0.349^{* * *}$ & $-0.191^{* * *}$ & $0.374^{* * *}$ & ns & $-0.186^{* * *}$ & $0.133^{*}$ & $0.266^{* * *}$ & ns \\
\hline (Z)-2-Octenal & $0.430^{* * *}$ & $-0.185^{* * *}$ & $0.438^{* * *}$ & $-0.123^{*}$ & $-0.212^{* * *}$ & $0.199^{* * *}$ & $0.331^{* * *}$ & ns \\
\hline (E)-2-Nonenal & $0.369^{* * *}$ & $-0.175^{* * *}$ & $0.392^{* * *}$ & ns & $-0.167^{* * *}$ & $0.112^{*}$ & $0.288^{* * *}$ & ns \\
\hline$(E, E)-2,4-$ Nonadienal & $0.225^{* * *}$ & $-0.125^{*}$ & $0.239^{* * *}$ & ns & ns & ns & $0.169^{* * *}$ & ns \\
\hline (E)-2-Undecenal & $0.654^{* * *}$ & $-0.335^{* * *}$ & $0.617^{* * *}$ & $-0.119^{*}$ & $-0.270^{* * *}$ & $0.289^{* * *}$ & $0.369^{* * *}$ & ns \\
\hline
\end{tabular}




\begin{tabular}{|c|c|c|c|c|c|c|c|c|}
\hline$(E, Z)-2,4$-Decadienal & $0.120^{*}$ & ns & $0.159^{* *}$ & $-0.108^{*}$ & ns & ns & $0.178^{* * *}$ & ns \\
\hline$(E, E)-2,4$-Decadienal & $0.378^{* * *}$ & $-0.150^{* *}$ & $0.396^{* * *}$ & $-0.134^{* *}$ & $-0.169^{* * *}$ & $0.116^{*}$ & $0.293^{* * *}$ & ns \\
\hline Phenylacetaldehyde & ns & ns & ns & $0.225^{* * *}$ & ns & ns & ns & ns \\
\hline Ethyl-hexanoate & $0.542^{* * *}$ & $-0.284^{* * *}$ & $0.426^{* * *}$ & ns & $-0.230^{* * *}$ & $0.369^{* * *}$ & $0.194^{* * *}$ & ns \\
\hline Ethyl-octanoate & $0.635^{* * *}$ & $-0.355^{* * *}$ & $0.636^{* * *}$ & $-0.237^{* * *}$ & $-0.260^{* * *}$ & $0.406^{* * *}$ & $0.374^{* * *}$ & ns \\
\hline 2-Butanone & ns & ns & ns & ns & ns & ns & ns & ns \\
\hline 2-Heptanone & $0.579^{* * *}$ & $-0.337^{* * *}$ & $0.602^{* * *}$ & $-0.130^{*}$ & $-0.265^{* * *}$ & $0.331^{* * *}$ & $0.390^{* * *}$ & ns \\
\hline 3-Octanone & $0.231^{* * *}$ & ns & $0.267^{* * *}$ & $-0.143^{* *}$ & $-0.137^{* *}$ & $0.103^{*}$ & $0.276^{* * *}$ & ns \\
\hline 2-Octanone & $0.426^{* * *}$ & $-0.209^{* * *}$ & $0.459^{* * *}$ & $-0.149^{* *}$ & $-0.186^{* * *}$ & $0.225^{* * *}$ & $0.275^{* * *}$ & ns \\
\hline 2-Nonanone & $0.279^{* * *}$ & $-0.146^{* *}$ & $0.302^{* * *}$ & $-0.104^{*}$ & $-0.142^{* *}$ & $0.191^{* * *}$ & $0.265^{* * *}$ & ns \\
\hline 1-Octen-3-one & $0.144^{* *}$ & ns & $0.198^{* * *}$ & $-0.183^{* * *}$ & ns & ns & $0.195^{* * *}$ & ns \\
\hline 3-Octen-2-one & $0.300^{* * *}$ & $-0.157^{* *}$ & $0.319^{* * *}$ & $-0.123^{*}$ & $-0.147^{* *}$ & $0.121^{*}$ & $0.216^{* * *}$ & ns \\
\hline 3-Nonen-2-one & $0.206^{* * *}$ & $-0.123^{*}$ & $0.227^{* * *}$ & ns & $-0.136^{* *}$ & ns & $0.164^{* *}$ & ns \\
\hline 2,3-Octanedione & ns & ns & $0.105^{*}$ & $-0.105^{*}$ & ns & ns & $0.177^{* * *}$ & ns \\
\hline 2-Pentylfuran & $0.714^{* * *}$ & $-0.382^{* * *}$ & $0.662^{* * *}$ & ns & $-0.281^{* * *}$ & $0.323^{* * *}$ & $0.379^{* * *}$ & ns \\
\hline TBARS & 1 & $-0.524^{* * *}$ & $0.819^{* * *}$ & ns & $-0.282^{* * *}$ & $0.463^{* * *}$ & $0.438^{* * *}$ & ns \\
\hline Raw meat & & 1 & $-0.656^{* * *}$ & ns & $0.543^{* * *}$ & $-0.382^{* * *}$ & $-0.272^{* * *}$ & $-0.251^{* * *}$ \\
\hline Rancid & & & 1 & $-0.147^{* *}$ & $-0.455^{* * *}$ & $0.450^{* * *}$ & $0.503^{* * *}$ & ns \\
\hline Mettalic & & & & 1 & ns & ns & ns & $0.190^{* * *}$ \\
\hline Sweet & & & & & 1 & $-0.288^{* * *}$ & $-0.322^{* * *}$ & $-0.107^{*}$ \\
\hline Moisty & & & & & & 1 & $0.269^{* * *}$ & ns \\
\hline Cooked meat & & & & & & & 1 & ns \\
\hline
\end{tabular}

4 ns: $P>0.05,{ }^{*}: P \leq 0.05,{ }^{* *}: P \leq 0.01,{ }^{* * *} P \leq 0.001$. 